San Jose State University

SJSU ScholarWorks

Master's Theses

Master's Theses and Graduate Research

1993

\title{
Effects of a Psychological Skills Educational Program (PSEP) on free throw shooting for male high school basketball players
}

Rob Wojtkowski

San Jose State University

Follow this and additional works at: https://scholarworks.sjsu.edu/etd_theses

\section{Recommended Citation}

Wojtkowski, Rob, "Effects of a Psychological Skills Educational Program (PSEP) on free throw shooting for male high school basketball players" (1993). Master's Theses. 657.

DOI: https://doi.org/10.31979/etd.8jh6-z2jz

https://scholarworks.sjsu.edu/etd_theses/657

This Thesis is brought to you for free and open access by the Master's Theses and Graduate Research at SJSU ScholarWorks. It has been accepted for inclusion in Master's Theses by an authorized administrator of SJSU ScholarWorks. For more information, please contact scholarworks@sjsu.edu. 


\section{INFORMATION TO USERS}

This manuscript has been reproduced from the microfilm master. UMI films the text directly from the original or copy submitted. Thus, some thesis and dissertation copies are in typewriter face, while others may be from any type of computer printer.

The quality of this reproduction is dependent upon the quality of the copy submitted. Broken or indistinct print, colored or poor quality illustrations and photographs, print bleedthrough, substandard margins, and improper alignment can adversely affect reproduction.

In the unlikely event that the author did not send UMI a complete manuscript and there are missing pages, these will be noted. Also, if unauthorized copyright material had to be removed, a note will indicate the deletion.

Oversize materials (e.g., maps, drawings, charts) are reproduced by sectioning the original, beginning at the upper left-hand corner and continuing from left to right in equal sections with small overlaps. Each original is also photographed in one exposure and is included in reduced form at the back of the book.

Photographs included in the original manuscript have been reproduced xerographically in this copy. Higher quality $6 " \mathrm{x} 9$ " black and white photographic prints are available for any photographs or illustrations appearing in this copy for an additional charge. Contact UMI directly to order.

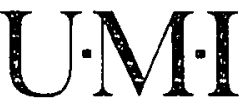

University Microfilms International

A Bell \& Howell Information Company 
Order Number 1354172

Effects of a Psychological Skills Educational Program (PSEP) on free throw shooting for male high school basketball players

Wojtkowski, Rob Edward, M.A.

San Jose State University, 1993

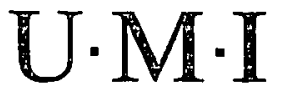

300 N. Zeeb Rd.

Ann Arbor, MI 48106 



\author{
EFFECTS OF A \\ PSYCHOLOGICAL SKILLS EDUCATIONAL PROGRAM (PSEP) \\ ON FREE THROW SHOOTING \\ FOR MALE HIGH SCHOOL BASKETBALL PLAYERS
}

\author{
A Thesis \\ Presented to \\ The Faculty of the Department of Human Performance \\ San Jose State University
}

In Partial Fulfillment

of the Requirements for the Degree

Master of Arts

By

Rob Wojtkowski

August, 1993 
APPROVED FOR THE DEPARTMENT OF HUMAN PERFORMANCE

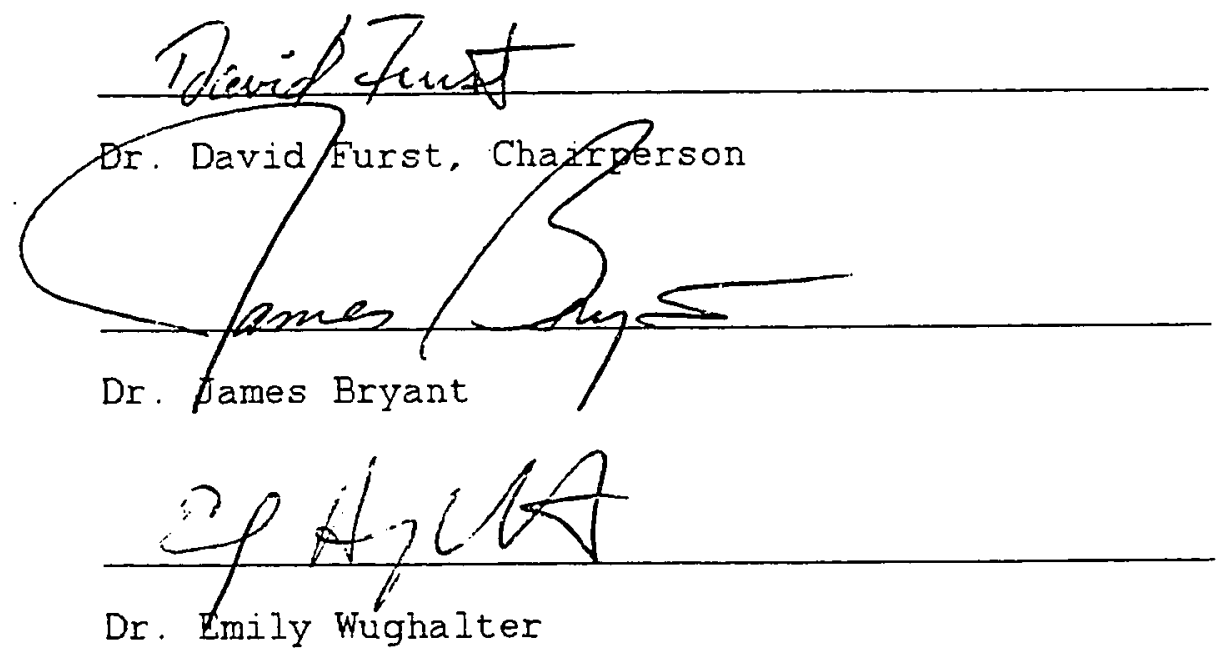

APPROVED FOR THE UNIVERSITY

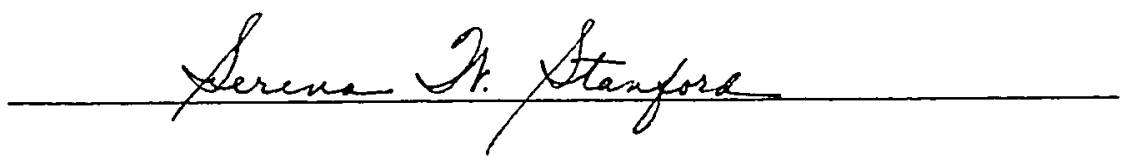




\section{ABSTRACT \\ EFFECTS OF A PSYCHOLOGICAL SKILLS EDUCATIONAL PROGRAM (PSEP) ON FREE THROW SHOOTING FOR \\ MALE HIGH SCHOOL BASKETBALL PLAYERS \\ by Rob Wojtkowski}

The purpose of the study was to investigate the effects the Psychological Skills Educational Program (PSEP) has on free throw shooting for male high school basketball players. Fourteen subjects were used to collect free throw shooting scores by shooting 20 discontinuous and 20 continuous free throws. Subjects were either placed into a PSEP group or attention-control group. During the 18 days of training. subjects in the PSEP group were taught progressive relaxation, imagery, cognitive restructuring, and the use of a pre-performance routine as outlined by Boutcher and Rotella (1987). In contrast, the attention-control group was given general information on basketball. Post-test free throw shooting data and questionnaires were analyzed. Results of this study indicated that there was no difference between the PSEP group and attention-control group on free throw shooting accuracy. However, the results of the questionnaires indicated that the subjects in the PSEP group felt their training was beneficial. 


\section{ACKNOWLEDGEMENTS}

I would like to extend my appreciation and gratitude to those individuals who actively participated in accomplishing this thesis.

To James Bryant, Committee Member, for his expertise in research design, knowledge of basketball shooting, and encouragement he gave me throughout my research.

To Emily Wughalter, Committee Member, for her expertise in statistics, research design, and motor learning, and her wilingness to assist me in the many details before, during, and after the research.

To David Furst, Committee Chair, for his encouragement and effort, ability to pass his knowledge of research design, flexibility in helping me reach the many deadlines, and most of all his excellent example as a professor and scientist.

To my family, friends, and players for encouraging me and giving me support. 
Table of Contents

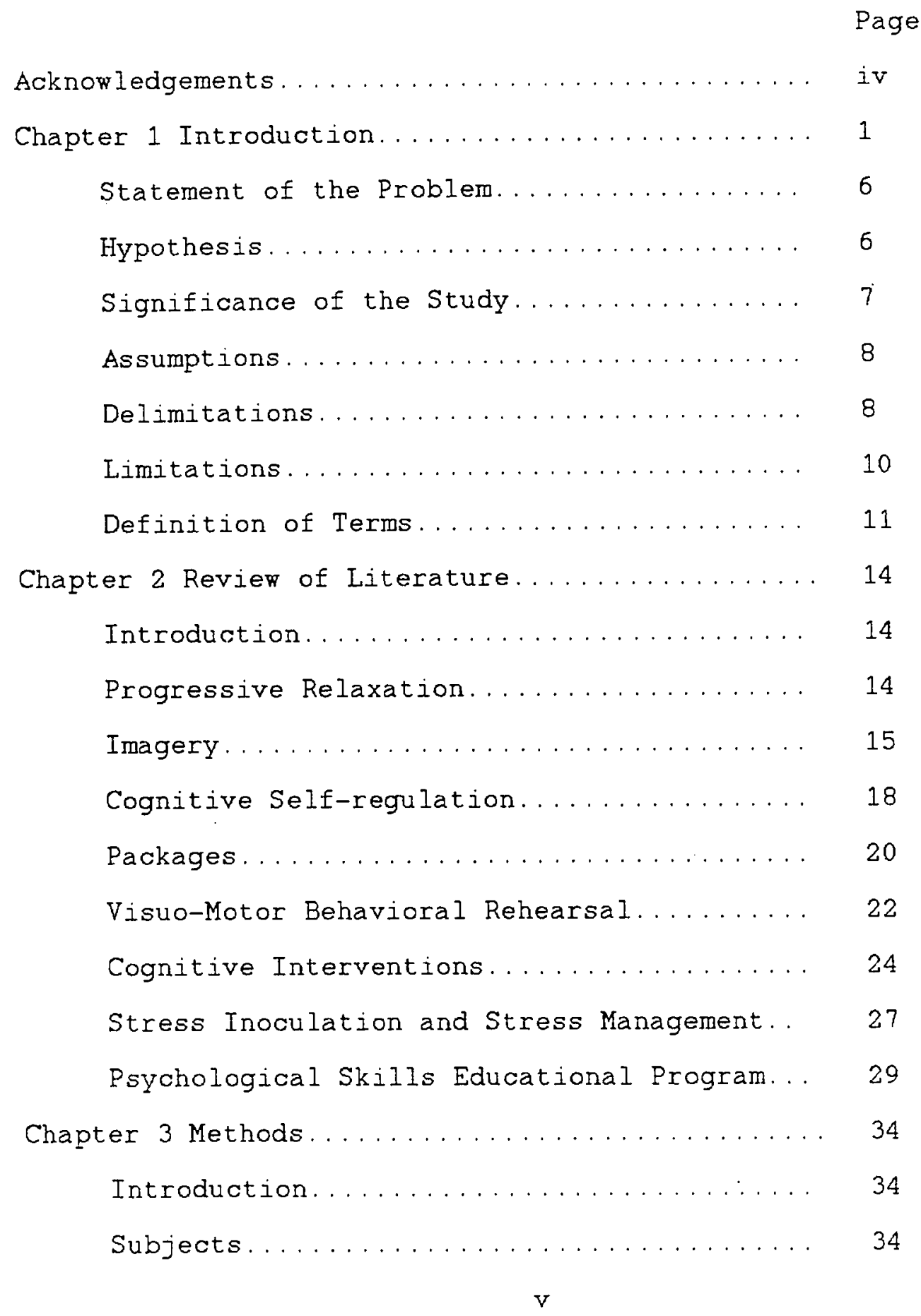


Instruments ................. 35

Procedures...................... 37

Design...................... 43

Analysis..................... 43

Chapter 4 Results and Discussion............ 44

Results.................... 44

Discussion................... 48

Chapter 5 Conclusions and Recommendations...... 53

Conclusions.................... 53

Recommendations................. 54

References........................ 56

Appendices....................... 63

Appendix A, pre-shot Routine........... 63

Appendix B, Consent Form............. 64

Appendix C, Pre-test Questionnaire........ 66

Appendix D, Shooting Video............ 67

Appendix $E, \operatorname{Iog} B o o k \ldots \ldots \ldots \ldots \ldots$

Appendix F, Breathing Technique......... 70

Appendix G, Progressive Relaxation........ 71

Appendix H, Modified Progressive Relaxation 76

Appendix I, Thought Stopping.......... 78

Appendix J, Cognitive Restructuring....... 80

Appendix K. Mini-relaxation Plan......... 82

Appendix I, PSEP Post Ouestionnaire....... 83 
Appendix M, Control Post Questionnaire.... 84

Appendix N, PSEP Post Ouestionnaire Results 85

Appendix 0, Control Post Questionnaire

Results.............. 86

vii 
Table of Tables

Table

Page

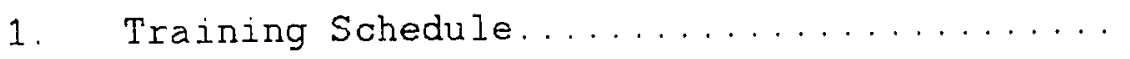

41

2. Pre-test Means of Continuous and

Discontinuous Free Throw Shooting Scores

and ANOVA Information.............. 44

3. Pre-test Means of Continuous and

Discontinuous Free Throw Shooting for

Shooting Order and ANOVA information.......

4. Post-test Means of Continuous and

Discontinuous Free Throw Shooting Scores

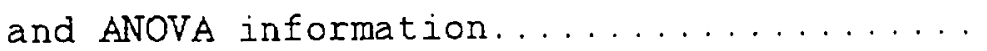

5. Post-test ANOVA with Pairwise Comparisons

for PSEP, Attention-control, Continuous,

and Discontinuous Free Throw Shooting..... 
CHAPTER 1

Introduction

In the recent years, there has been an enormous increase in performance enhancement techniques to help athletes (Fenker \& Lambiotte, 1987; Gauron, 1986). Athletes and coaches are beginning to realize that psychological performance enhancement techniques are a necessity in athletics. As Gauron (1986) stated, "coaches and athletes have refined physical training programs just about as far as they can. In a continuing search for the extra edge to stimulate ever-rising performance standards, attention has focused on the mental aspect of performance" (p. 91). Gauron later states that athletes have claimed that mental strategies can account for almost $90 \%$ of athletic performance, but there is still very little mental training being emphasized throughout athletics. Although there seems to be a lack of mental training for non-elite athletes, elite athletes have been using performance enhancement techniques like mental practice (Feltz \& Landers, 1983) and imagery (Smith, 1987) for years. In fact, both professional golfer Jack Nicklaus and basketball player Magic Johnson have indicated that they use imagery during competition to help enhance performance (Bird \& Cripe, 1986). Furthermore, the Olympic games have seen many of its athletes rely heavily on performance enhancement techniques such as relaxation and 
imagery (Suinn, 1976; Ungerleider, 1985; Wrisberg \& Anshel, 1989). However, there is a lack research that uses youth athletes to study the effects of performance enhancement techniques such as progressive relaxation, imagery, and cognitive self-regulation.

One of the first performance enhancement techniques used in sports was progressive relaxation which was developed by Edmund Jacobson (Greenberg, 1987). Using the Jacobson technique, the athlete contracts and then relaxes muscles in order "to recognize more readily what muscle tension feels like" (Greenberg, 1987, p. 161). Another performance enhancement technique that is often taught with progressive relaxation is imagery. Imagery is "a well-controlled copy of experience, a sort of body-thinking similar to the powerful illusion of certain dreams at night" (Suinn, 1976, p. 41).

Another performance enhancement technique now being used in athletics is cognitive self-regulation. Cognitive selfregulation investigates how our "attitudes, perceptions, thoughts, and internal dialogue" can affect performance (Gauron, 1986, p. 91). Two cognitive self-regulation techniques are thought stopping and cognitive restructuring. Thought stopping is a technique "whereby the stressed person internally breaks the anxious cycle by abruptly leavirig the obsessional thoughts" (Girdano \& Everly, 1986, p. 133). Cognitive restructuring is a variation of thought stopping 
"that relates to changing interpretation or changing the meaning attached to a particular event" (Gauron, 1986, p. 95) .

Although performance enhancement techniques such as progressive relaxation, imagery, and cognitive restructuring can be beneficial, each of these techniques alone might not be as porerful as a combination of techniques (Seabourne, Weinberg, \& Jackson, 1985). One of the first intervention packages that combined performance enhancement techniques is Visuo-Motor Behavior Rehearsal (VMBR). VMBR was developed by Suinn using three steps: progressive relaxation, the practice of imagery, and using imagery to practice a skill in a lifelike environment when stress is present (Suinn, 1976).

Another intervention package used to help athletic performance is Stress Inoculation Training (SIT). SIT was developed by Meichenbaum and consists of three phases: conceptualization, skill acquisition and rehearsal, and application through follow-through (Meichenbaum \& Deffenbacher, 1988). A package that closely resembles SIT is Stress Management Training (SMT). SMT has the same three phases of conceptualization, skill acquisition, and application as SIT. However, during the third phase of SMT "the feelings experienced in the actual stress situation are induced" (Cox, 1990, p. 179). 
A package that resembles SIT is called Psychological Skills Educational Program (PSEP). The PSEP was developed by Boutcher and Rotella (1987) and consists of four phases: sport analysis, individual assessment, conceptualization/ motivation, and mental skill development. PSEP differs from VMBR, cognitive interventions, SIT, and SMT for a variety of reasons. First, the PSEP deals only with closed skills. A closed skill is performed in an environment that is stable, while an open skill is is performed in an environment that is constantly changing (Schmidt, 1988). Thus, with closed skills an athlete can use techniques such as imagery, relaxation, and cognitive self-regulation to exactly practice competitive situations because there is no difference in motor technique between practice and competition.

Secondly, in PSEP the instructor must be familiar with the closed skill being used. Blame for poor performance should not be solely placed on the athlete's mental strategies when the athlete does not have the proper technique to complete the skill (Cox, 1990). By understanding the physical components of the closed skill, the instructor can assess whether the problem is physical or mental. Although other packages might imply that the researcher understand the skill being assessed, no other package stresses this point. 
Next, the PSEP differs from other packages in that individualizing for each athlete is a high priority. Packages that are individualized allow each athlete to use techniques that will be most beneficial, as opposed to using just one technique that may or may not work for the particular athlete (Seabourne, et al., 1985). Although individualizing in PSEP is beneficial for the athlete, in order to choose appropriate techniques, the athlete must experience many different techniques and this process can take a great deal of time.

Another difference between the PSEP and other packages is the use of a pre-performance routine. There has been considerable research indicating that a pre-performance routine is essential to successful performance in closed skills (Cohn, Rotella, \& Lloyd, 1990; Gayton, Cielinski, Erancis-Keniston, \& Hearns, 1989; Lobmeyer \& Wasserman, 1986; Wrisberg \& Pein, 1992). A pre-performance routine is "a combination of cognitive and behavioral strategies used prior to the execution of motor skilis" (Cohn, et al., 1990, p. 33). By focusing on pre-performance routines, mental strategies can be cued during each individual's routine. These cued strategies give the athlete a "map" to complete the skill during stressful situations.

Lastly, the PSEP uses goal setting to help with compliance during the acquisition of performance enhancement 
techniques and focusing techniques. Clear and objective goals should be set by the athlete and instructor to give the athlete incentive to continue to use the PSEP. As Boutcher and Rotella (1987) state, "only by objective evaluation can the program be continually changed and adjusted to meet the needs of the athlete" (p. 135).

As stated earlier, the PSEP differs in many ways from other cognitive interventions, VMBR, SMT, and SIT which have been tested empirically. However, there has been no empirical research using the PSEP, even though authors have intuitively stated that it would be effective (Cox, 1990). Statement of the Problem

To test the effects a Psychological Skills Educational Program (PSEP) had on free throw shooting performance for male high school basketball players.

Hypothesis

There were four hypotheses in the current research.

1. PSEP and attention-control groups do not differ in pretest free throw shooting performance scores.

2. Order of shooting, continuous/discontinuous and discontinuous/continuous, does not affect pre-test free throw shooting performance scores.

3. PSEP does not affect post-test free throw shooting performance scores. 
4. PSEP and type of shooting (continuous and discontinuous) will not affect free throw shooting on post-test scores. Significance of the Study

There were three reasons why the current study is significant. First, although the PSEP has been described in a theoretical matter by Boutcher and Rotella (1987), there has not been any study published that tests this package. Therefore, this study attempted to quantify the performance differences between a PSEP treatment group and an attentionplacebo group. The results from this study can then be used as possible support for using or not using the PSEP.

Next, the PSEP stresses incorporating performance enhancement techniques into the pre-performance routine. Packages such as VMBR, SIT, SMT, and cognitive interventions have been researched; however, none of the packages found in the review of literature emphasized the use of performance enhancement techniques with a pre-performance routine. Thus, the results of this research can possibly indicate whether or not combining a pre-performance routine and performance enhancement techniques is appropriate.

Lastly, this study used high school freshman and sophomores as subjects which will add to the small amount of literature currently available on how packages affect nonelite and non-collegiate athletes (Greenspan \& Feltz, 1989). Previous research has suggested that investigation is needed 
to determine if young athletes can generalize learned cognitive strategies to actual competitions (Wrisberg \& Anshe 1, 1989). Furthermore, Hughes (1990) suggests that performance enhancement techniques might be a key ingredient to achieve athletic excellence in high school.

Assumptions

There were four basic assumptions in this study. 1. Subjects in the attention-control group did not use the PSEP or learn about the PSEP from the treatment group. In order to limit the amount of commuication of training material between the PSEP and control groups, the researcher de-emphasized any importance of information that one group is attaining in comparison to the other group.

2. All subjects responded truthfully on questionnaires and $\log$ books.

3. The PSEP was presented as Boutcher and Rotella (1987) meant it to be presented.

4. Shooting discontinuous and continuous free throws during testing represented actual game and practice performance. Delimitations

The study was delimited in the following manner. 1. Type of athlete in study - Only high school male freshman and sophomore basketball players from a single team were used in this study. Thus, results can not be expanded to other gender and age groups. The motivation and 
familiarity with the PSEP were controlled by having the researcher and the coach assume the same person. Thus, the researcher scheduled and ran practices that allowed for full compliance with the PSEP guidelines. As Boutcher and Rotella (1987) state in their sumary, future research should study how athletes react to the program. By having the coach be the researcher, the athletes could feel more comfortable with the material, due to the trust built over the time already spent between each player and the coach.

2. Time of year - The need to have athlete compliance was an essential part of the PSEP program as explained by Boutcher and Rotella (1987) in the third phase. Previous research has suggested that conducting the experiment during the season will control "extraneous factors such as motivation slumps" (Gray \& Fernandez, 1989, p. 45). Thus, this study was conducted during the actual competitive season. Different results might be found by conducting this study during the pre-season, post-season, or summer.

3. Sample size - Although previous research testing packages have used sample sizes comparable to the sample size in the present study (Crocker, Alderman, \& Smith, 1988; Hall \& Erffmeyer, 1983; Noel, 1980; Weinberg, Seabourne, \& Jackson, 1981), the small sample of 14 in this study makes it difficult to generalize this study's findings. However, because of the time needed to teach a variety of performance 
enhancement techniques, the sample size needed to be small in order to individualize the PSEP.

Limitations

There were three limitations in the current research. 1. Answers on questionnaires and log books - During the second phase, questionnaires were used to assess each individual and these questionnaires could possibly be answered falsely. Also, log books were kept by each individual during the study as manipulation checks for homework assignments. These log books have been used in previous research to monitor whether or not performance enhancement techniques were being practiced at home (Hughes, 1990; Kendall, et al., 1990; Seabourne, Weinberg, \& Jackson, 1984; Seabourne, et al., 1985). Thus, there was no way to discover if the athletes are answering truthfully or if they were answering the questions in a way that they feel the researcher would like them answered.

2. Time - Although the current study had a training period as long or longer than previous research (Hall \& Erffmeyer. 1983; Hughes, 1990; Kendall, et al., 1990; Noel, 1980; Weinberg, Chan, \& Jackson, 1983; Weinberg, et al., 1981; Wrisberg\& Anshel, 1989), Seabourne, et al. (1984) have suggested that a 16 week program is more effective than programs that are only 8 weeks in length because of the time needed to develop performance enhancement techniques. 
However, in the Seabourne, et al. (1984) study, subjects met only twice a week, while in the current study subjects met on an average of 4 days a week. Thus, the amount of time spent between the researcher and the athlete was comparable to the Seabourne, et al. (1984) study.

3. Communication between groups - There may have been cross talk between the PSEP and attention-control groups. The researcher could not control the cross talk that might have taken place between treatment groups.

Definition of Terms

1. Attention-placebo control group - the group of subjects that watched videos, read articles and books on basketball during their training.

2. Cognitive self-regulation - the ability to control and change one's own thinking and gain greater control of internal processes such as "attitudes, perceptions, thoughts, and internal dialogue" (Gauron, 1986).

3. Continuous free throw shooting - subjects shoot 20 continuous free throw at a basket with the number of total made shots and basket location recorded.

4. Discontinuous free throw shooting - three subjects place themselves at a basket for the discontinuous shooting. One subject is at the free throw line while the other two are at each side of the free throw area. After the shooter completes two free throws, all three subjects run from one 
sideline, to the other sideline, and back to the basket. After returning to the basket, a new shooter attempts two free throws. After the second shooter completes the two shots, all the subjects again run from one sideline, to the other sideline, and back to the basket. This process continues until a total of 20 shots is completed by each subject.

5. Imagery - "a well-controlled copy of experience, a sort of body-thinking similar to the powerful illusion of certain dreams at night" (Suinn, 1976).

6. Mental practice - using imagery to practice a specific skill.

7. Package - any combination of performance enhancement techniques used to help improve performance for athletes. 8. Performance enhancement technique - a single technique such as progressive relaxation, imagery, or cognitive selfregulation that is used to help athletes improve their performance through mental intervention.

9. Pre-performance routine - "a combination of cognitive and behavioral strategies used prior to the execution of motor skills" (Cohn, et al., 1990). 10. Progressive relaxation - "a technique used to induce nerve-muscle relaxation. . contract a muscle group, then relax it, moving (or progressing) from one muscle group to another" (Greenberg, 1987, p. 161). 
11. PSEP group - group of subjects that were taught and practice the PSEP during their training. 
CHAPTER 2

Review of Literature

Introduction

The review of literature is divided into three parts. First, performance enhancement technique literature is reviewed for progressive relaxation, imagery, and cognitive self-regulation. Next, literature on the packages of VMBR, cognitive intervention, SIT, SMT, and PSEP is reviewed.

Third, throughout the review of literature, studies with methods of importance to the current study will be highlighted.

Progressive Relaxation

As stated in the introduction, progressive relaxation was developed by Edmund Jacobson and has the athlete contract and then relax muscles in order "to recognize more readily what muscle tension feel like" (Greenberg, 1987, p. 161). Once the athlete learns to distinguish between a tense and relaxed muscle, which may take weeks of training, the athlete can "invoke the relaxation response in a matter of seconds" (Cox, 1990, p.150). Progressive relaxation can be taught through an instructor or by audio tape recordings of an instructor. After the complete form of progressive relaxation is mastered, mini versions of the technique can be taught to the athlete; in order to use less time and still maintain practice by the athlete (Greenberg, 1987). 
Relaxation techniques can be used throughout competition. McAuley and Rotella (1982) outline a treatment plan that uses relaxation prior to performance, during performance, and following performance. Although relaxation is a valuable part of many packages and has been shown to improve performance in case studies (Nideffer \& Deckner, 1970), researchers have failed to find performance improvements with progressive relaxation alone (Cox, 1990). Relaxation does reduce anxiety levels; however, it is unclear how relaxation affects performance (Onestak, 1992). Weinberg, et al. (1983), using 40 college students, compared the affects of an imagery, relaxation, relaxation plus imagery, and placebo control group on free throw performance. Results indicated that only the imagery group showed significant improvements in performance. Although relaxation did not lead to direct performance improvement, many researchers state that relaxation is a valuable skill that can enhance imagery (Kendall, et al., 1990; Smith, 1987).

Imagery

While the literature on how progressive relaxation can effect performance is quite small, the literature on how imagery or mental practice can effect performance is extensive. As stated previously, many professional, Olympic, and world class athletes have reported the use of imagery to help their performance. Imagery differs from mental practice 
in that imagery is "a well-controlled copy of experience, a sort of body-thinking similar to the powerful illusion of certain dreams at night" (Suinn, 1976), while mental practice is simply using imagery to practice a skill through repetition.

In a meta-analysis of mental practice, Feltz and Landers (1983) concluded that mental practice is somerhat better than no practice at all and that mental practice has more of an effect on the cognitive demands of sport rather than the motor or strength demands. An early study using high school basketball players studied the effects of mental practice on free throw performance (Clark, 1960). Results indicated that both the practice and mental practice groups showed improvement in performance, while the no practice group showed no improvement. Furthermore, both the varsity and junior varsity players showed improvement, while the novice group did not show any improvement.

In a related study, Ziegler (1987), using 93 university students, compared the effects imagery has on free throw performance. Groups consisted of a control, physical practice only, passive imagery, active imagery (standing with eyes closed and going through motion of shot), and imagery with physical practice. Results indicated that both the active and imagery with physical practice improved significantly more than the physical practice only group. 
Further analysis showed that the less experienced subjects showed more improvements in shooting performance. These results conflict with the results in the Clark (1960) study that found the more experienced group showing the most improvement during treatment. The Ziegler (1987) study must be viewed with discretion because of the poor overall shooting performance $(20 \%-40 \%)$; thus, the results might have been different for a group of athletes who shoot a more reasonable percent $(50 \%-70 \%)$.

When trying to teach imagery to athletes, researchers need to be aware of the important aspects of imagery. Smith (1987) has listed 6 steps to help the development of imagery:

1) vividness and controllability

2) practice

3) attitude and expectation

4) previous experience

5) relaxed attention

6) internal vs. external imagery

Vividness refers to the ability to imagine events as "colorful, realistic, and involve the appropriate senses as well as related emotions" (Smith, 1987, p. 238). Controllability refers to "the ability to manipulate a person's mind" (p. 238). Attitude and expectation relates to practice because the athlete must know that skillful imagery does not occur over night and the athlete must allow time for 
the skill development. As stated previously, previous experience can have an effect on performance (Clark, 1960; Ziegler, 1987). Furthermore, a relaxed attention can be achieved by using progressive relaxation. Lastly, internal imagery refers to "viewing yourself through your own eyes," while external imagery refers to "viewing yourself through a movie camera." Internal imagery has been shown to be more powerful than external imagery (Hale, 1982; Harris \&

Robinson, 1986).

Cognitive Self-regulation

Besides progressive relaxation and imagery, another performance enhancement technique now being used in athletics is cognitive self-regulation. Cognitive self-regulation investigates how our "attitudes, perceptions, thoughts, and internal dialogue" can affect performance (Gauron, 1986, p. 91). Unlike the large amount of research investigating only imagery, cognitive self-restructuring has been researched by incorporating it into a package (Gauron, 1986; Hamilton \& Fremouw, 1985; Kendal1, et al., 1990; MaAuley \& Rotella, 1982). Tro techniques used in cognitive selfregulation are thought stopping and cognitive restructuring. Thought stopping is a technique "whereby the stressed person internally breaks the anxious cycle by abruptly leaving the obsessional thoughts" (Girdano \& Everly. 1986, p. 133). A simple thought stopping technique would be to first be aware 
of the negative thought, tell yourself to "Stop!", and then substitute a positive thought in the negative thought's place (Gauron, 1986).

A second technique used in cognitive self-regulation is cognitive restructuring. Cognitive restructuring is a variation of thought stopping "that relates to changing interpretation or changing the meaning attached to a particular event" (Gauron, 1986, p.95). Gauron explains that when using cognitive restructuring an athlete would simply look at the event in a ray that is completely opposite. For example, instead of viewing a close defeat as being negative, the athlete would adjust his or her perspective and view the close defeat as a good game versus a very good opponent, in which the outcome of the game could have gone either way. Thus, the athlete is able to look at the "brighter side" of any negative outcome which would prevent any negative thoughts to carry over to the next competition.

Although cognitive self-regulation has not been studied by itself, research studies combining cognitive selfregulation and other performance enhancement techniques have been studied. Kendall, et al. (1990), using four female intercollegiate basketball players, studied the effects of a package using relaxation, imagery, and cognitive selfregulation techniques on a defensive skill in basketball. 
Results indicated that the intervention was clearly effective.

In another study using a cognitive self-regulation technique, Hamilton and Fremouw (1985) used three Division-2 basketball players to study the effects of relaxation and cognitive self-regulation on free throw performance. Results indicated that the subjects improved by $88 \%, 78 \%$, and $50 \%$ over the 4 week period. Furthermore, "cognitive changes were found in the percentage of positive coping strategies being used after training" (p. 483). Thus, although cognitive self-regulation techniques are not often used alone in research studies, a package using cognitive self-regulation can be quite effective in improving performance.

\section{Packages}

Although performance enhancement techniques such as progressive relaxation, imagery, and cognitive restructuring can be beneficial, each of these techniques alone might not be as powerful as a combination of techniques (Seabourne, Weinberg, \& Jackson, 1985). A "package" of performance enhancement techniques can be more beneficial than a single technique for a variety of reasons. First, some performance enhancement techniques are perfect complement for one another. For example, relaxation is used with imagery training to create a calm environment which allows for clarity of the image (Kendall, Hrycaiko, Martin, \& Kendall, 
1990; Smith, 1987). Furthermore, it has been reported that cognitive self-regulation with relaxation and imagery can have a positive impact on performance (Hamilton \& Fremouw, 1985).

Secondly, a package will allow each athlete to gain an overall understanding of how each performance enhancement technique can help performance (Boutcher \& Rotella, 1987). Thus, the athlete having been educated on a variety of performance enhancement techniques can emphasize particular techniques within the package that he or she feels will be most beneficial (Seabourne, Weinberg, Jackson, \& Suinn, 1985). As Seabourne, et al. (1985) state, "coaches sometimes teach their players a relaxation technique in an attempt to enhance performance. This strategy may help some of the players who get anxious or uptight before competition, but it may be unnecessary or even detrimental for others who are not anxious or who are capable of controlling their anxiety" (pp. 40-41)

Lastly, by empowering the athlete to take control of his or her own mental strategies, coaches will not have to attempt to motivate their players before games. Instead of "pep talks," the coach could block off a short "quiet time for the athletes to use the strategies they had learned to reach their optimal arousal/focused state" (Fenker \& Lambiotte, 1987). Thus, by empowering the athletes with the 
responsibility of attaining their own level of arousal, the coach could use "pep talk" energy to concentrate on game strategies or perhaps to relax or focus the team.

Visuo-Motor Behavior Rehearsal

One of the first intervention packages that combined performance enhancement techniques is Visuo-Motor Behavior Rehearsal (VMBR). VMBR was developed by Suinn using three steps: progressive relaxation, the practice of imagery, and using imagery to practice a skill in a lifelike environment when stress is present (Suinn, 1976). One of VMBR's advantages is the combination of relaxation and imagery. As stated earlier, relaxation creates an atmosphere that promotes quality imagery (Kendall, et al., 1990; Smith, 1987). Another advantage of using VMBR is the application of relaxation and imagery to real life conditions in the third phase of the package. During the third phase of VMBR, athletes gain valuable knowledge because "going through these stressful experiences mentally should make it easier to deal with the stress in actual competitions" (Cox, 1990, p.175). Suinn (1976) first used VMBR with individual Olympic athletes. In these individual case studies, Suinn found that the treatment was successful in improving performance. Furthermore, research has indicated that VMBR training can lead to increase performance for skills such as serving in tennis (Noel, 1980), karate performance (Seabourne, et al., 
1984; Weinberg, et al., 1981), and free throw shooting in basketball (Gray \& Fernandez, 1989; Hall \& Erffmeyer, 1983).

In order to teach VMBR, homework assignments (Noel, 1980; Seabourne, et al., 1984; Weinberg, et al., 1981) have been used to supplement teaching sessions to help subjects learn VMBR. Furthermore, log books have been used as a manipulation check to monitor use of homework practice (Seabourne, et al., 1984). Noel (1980) presented each subject with an audio tape that had VMBR training included. By giving homework, log books, and audio tapes, researchers have tried to increase the time subjects are exposed to VMBR treatment.

Hall and Erffmeyer (1983), using 10 female college basketball players, studied the difference of VMBR with and without modeling. Modeling was done by presenting a video tape of an experienced female basketball player executing free throws. The modeling group was given VMBR training and a model to be used in their own visualization. Results indicated that only the VMBR plus modeling group showed improvements in performance. The results of this study are important because "earlier studies had often assumed that subjects could use visual imagery without training. However, the effective use of any type of imagery requires practice. The use of visual cues through modeling proved to be very 
useful in providing an effective means of enhancing VMBR techniques" (p. 346).

In a related study, Gray and Fernandez (1989) also studied female basketball players using VMBR plus modeling. Unlike the previous study that only used continuous free throw shooting to test performance (Hall \& Erffmeyer, 1983), this study had subjects shoot both continuous free throws and discontinuous free throw that would represent game like conditions (Gray \& Fernandez, 1989). Discontinuous free throw shooting was accomplished having "one player initially shot five free throws with the other five players watching from the perimeter of the lane. After the fifth shot, all players ran to the opposite baseline and back to the original basket" (Gray \& Fernandez, 1989, p. 43). Results indicated that VMBR training plus modeling can influence discontinuous performance. Researchers concluded that "the fact that improvement was significant only for the game-simulated free throw position indicates that both the VMBR videotape and the testing protocol should simulate game conditions as closely as possible for optimum results" (Gray \& Fernandez, 1989, p. 44$)$.

\section{Cognitive Interventions}

Besides VMBR, there has been an increase in assorted packages that resemble the guidelines and techniques of VMBR. These packages are labelled cognitive interventions and they 
have been used with gymnastics (McAuley \& Rotella, 1982), Olympic athletes (Ungerleider, 1985), basketball players (Kendall, et al., 1990; Meyers \& Schleser, 1980), and a college football team (Fenker \& Lambiotte, 1987). Some cognitive intervention packages combine only relaxation and imagery (Meyers, Schleser, \& Okwumabua, 1982; Ungerleider, 1985; Weinberg, Chan, \& Jackson, 1983; Wrisberg \& Anshel, 1989). Hughes (1990) used imagery and goal setting to help high school athletes with their performance in football and basketball. In recent years, intervention packages have combined cognitive self-regulation techniques with relaxation and imagery (Hamilton \& Fremouw, 1985; Kendall, et al., 1990; Meyers \& Schleser, 1980). These cognitive interventions differ from VMBR in that they do not use VMBR's third step of mentally rehearsing stressful situations, except for Meyers, et al. (1982).

Case studies have indicated that relaxation, imagery, and cognitive self-regulation (Meyers \& Schleser, 1980) or inoculation (Meyers, Schleser, \& Okwumabua, 1982) can have positive effects on basketball performance. Furthermore, a cognitive intervention combining imagery and goal setting has been shown to enhance sport skills for high school football and basketball player (Hughes, 1990). An entire college football team was taught a cognitive intervention technique using relaxation and imagery (Fenker \& Lambiotte, 1987). 
Results showed that not only did the players feel the technique was effective, the team had there best season in years.

Although there has been a variety of sports testing cognitive interventions, one sport that has received an abundance of testing is basketball (Hamilton \& Fremour, 1985; Kendall, et al., 1990; Meyers \& Schleser, 1980; Meyers, et al., 1982; Wrisberg \& Anshel, 1989). Hamilton and Fremouw (1985) using 3 college basketball players studied the effects of a cognitive intervention that used progressive relaxation, imagery, cognitive self-regulation. Homework was given to the subjects by presenting the performance enhancement techniques on audio tapes. Results indicated that both free throw shooting and cognitive coping strategies (the amount of positive and negative self-statements) improved. Researchers suggested that the "lack of control for attention effects" (p. 483) is an important issue. The use of an attention-placebo control group could help control for the attention effects problem.

Another cognitive intervention that used relaxation and imagery to improve free throw performance was developed by Wrisberg and Anshel (1989). This study used young athletes (10 -12 olds) during a week summer camp to test the effects of the treatment. Groups included an imagery with practice, imagery and attempted an arousal adjustments strategy. 
imagery combining a arousal adjustments strategy, and a control group. Results indicated that "mental imagery combined with arousal adjustment is a useful pre-shot cognitive strategy that young athletes may use to enhance free throw shooting performance" (p. 95).

Stress Inoculation Training and Stress Management Training

While there is a large amount of literature on the use of VMBR training in athletics, the literature on Stress Inoculation Training (SIT) and Stress Management Training (SMT) training is sparse. SIT was developed by Meichenbaum and consists of three phases: conceptualization, skill acquisition and rehearsal, and application through followthrough (Meichenbaum \& Deffenbacher, 1988). Relaxation, imagery, and cognitive self-regulation techniques are presented to the athlete throughout the three phases (Cox, 1985). SIT differs from the previous techniques in that in the conceptualization phase of SIT the athlete learns how anxiety affects performance and how performance enhancement techniques affect anxiety. Furthermore, SIT differs from VMBR in that SIT has the athlete guided "through a series of progressively more threatening situations" (Cox, 1990. p. 178). Thus, by practicing SIT with a variety of different stress levels, the athlete is able to create a more realistic atmosphere because stress levels do not occur at only one level. Cox continues to state that these threatening 
situations are presented through imagery, real life situations and films.

A package that closely resembles SIT is Stress Management Training (SMT). SMT has the same three phases of conceptualization, skill acquisition, and application as SIT. However, during the third phase of SMT "the feelings experienced in the actual stress situation are induced" (Cox. 1990, p. 179). Thus, the athlete learns to control his or her own emotions during a stressful situation.

SIT has been studied by Mace and Carroll (1989) using 18 gymnasts. A SIT and attention-placebo control group attended 7 sessions of treatment over a 2 week period. Results indicated that the SIT group showed a decrease in the levels of stress and increases in performance.

SMT has been studied by using high performance youth volleyball players (Crocker, et al., 1988). A treatment group was compared to a waiting list control group by analyzing negative self-talk and return of serve performance. Results indicated that the SMT group "emitted fewer negative thoughts in response to videotaped stressors and had superior service reception performance in a controlled practice compared to the control group" (p. 448).

In another study using youth volleyball players and the previous study's treatment groups (Crocker, 1989b), the control group showed less of a stress level than the SMT 
group. The researcher concluded that the results found might have been caused by a small sample size, inappropriate design, and effect constructs.

Ziegler, Klinzing, and Williamson (1982) compared SIT, SMT, and a control group. Using 8 male cross-country runners oxygen consumption and heart rate data were monitored. Results indicated that both the SIT and SMT showed significant differences in cardiorespiratory efficiency when compared to the control group. The results of this study, along with the results listed from previous study show that there is a need for more research showing the effects SIT and SMT have on performance for a variety of sports.

Psychological Skills Educational Program

One package that resembles SIT and SMT is the Psychological Skills Educational Program (PSEP). The PSEP was developed by Boutcher and Rotella (1987) and consists of four phases: sport analysis, individual assessment, conceptualization/motivation, and mental skill development. In the first phase, sport analysis, the instructor must first learn the appropriate motor skill technique being assessed. Sport analysis is very important because if the instructor does not know all the physiological, psychological, and technical aspects of the sport, he or she might not be able to assess the athlete properly. For example, a researcher might view an athlete as having psychological problems, when 
in reality the athlete could just be having a minor problem with their motor skill technique. Furthermore, the PSEP addresses only closed skills like free throw shooting in basketball or dart throwing. Thus, the researcher does not have to focus on the changing environmental factors that accompany open skills.

The second phase, individual assessment, uses questionnaires, interviews, and state and trait anxiety tests to assess current psychological levels. Athletes are encouraged to share thoughts about previous performance that pere both their worst and best. In this phase, video taping may be used in order to help the athlete assess his or her own weaknesses and give the researcher a means of individualizing error assessment.

The third phase, conceptualization and motivation, uses the individual assessments to help personalize discussions on how worry, anxiety, and lack of attentional focusing effects performance. Boutcher and Rotella (1987) state that "the essential aim. . is to get the athlete to understand how worry, preconceptions of failure, and a tendency to be overanalytical can dramatically affect the performance of skills that are best performed automatically or reflexively" (p. 132). Also, the athletes are told that they will need to be committed to this program and that their performance results will increase with their commitment to the program. 
One way to help increase with their commitment is to utilize goal setting. The authors believe that goal setting is the most effective strategy to foster both motivation and compliance during and after the PSEP training.

The fourth, and final phase, is development of skills. In this phase relaxation, imagery, cognitive self-evaluation, and attentional focusing are taught to the athletes by first having general skill development, followed by specific mental skill development, and concluded by individualized performance routines. Thus, the athlete is given a wealth of knowledge that will allow full understanding of each technique. Finally, the last step of phase four is to incorporate the techniques into each athlete's individual pre-performance routine. The pre-performance routine is used to organize and utilize each intervention strategy in a systematic way. The main difference between the PSEP and other packages is the use of a pre-performance routine. There has been considerable research indicating that a preperformance routine is essential to successful performance in closed skills (Cohn, et al., 1990; Gayton, et al., 1989; Lobmeyer \& Wasserman, 1986; Wrisberg \& Pein, 1992). A preperformance routine is "a combination of cognitive and behavioral strategies used prior to the execution of motor skills" (Cohn, et al., 1990). By focusing on pre-performance routines, mental strategies can be cued during each 
individual's routine. These cued strategies give the athlete a "map" to complete the skill during competitive situations that can be very stressful.

Research using pre-performance routines and golf performance has been investigated in the literature. Preperformance routines have been shown to help with college golf performance (Cohn, et al., 1990). Furthermore, research has concluded that focusing one's "attention on specific pords and thoughts and learning a set pattern of actions" (Boutcher \& Crews, 1987) can improve performance. However, not all levels of athletes will benefit from a preperformance routine because "beginners may need to first focus attention on learning the basic skills, and once such skills are pell-learned, the acquisition of a pre-shot routine may further enhance performance" (Crews \& Boutcher, 1986, p. 294).

Besides golf, basketball free throw shooting has been used to study pre-performance routines. Research has shown that a pre-performance routine compared to no routine at all (Gayton, et al., 1989; Lobmeyer \& Wasserman, 1986) or an inconsistent routine (Wrisberg \& Pein, 1992) can influence performance. Furthermore, Greider (1991) showed how performance enhancement techniques can be placed in a preshot routine for free throw shooting (Appendix A). The combining of a pre-shot routine and performance enhancement 
techniques is the most important difference between the PSEP and other packages, and this will be stressed throughout the study 


\section{CHAPTER 3}

\section{Methods}

Introduction

This study compared subjects who were PSEP trained and subjects who were given only general basketball knowledge. After training, differences between the PSEP and attentioncontrol groups were analyzed.

Subiects

Subjects consisted of 14 members of a male high school basketball team. Subjects were either freshman or sophomores with previous basketball experience ranging from 3 to 8 years. The subjects were either 14 or 15 years old. Research has generally suggested that there is a need for more studies using non-elite and non-collegiate athletes that shows how they perform using packages (Greenspan \& Feltz, 1989). Furthermore, researchers have indicated that implementing a relaxation and imagery package with a college team can have positive performance results (Fenker \& Lambiotte, 1987). In addition, Weinberg, et al. (1981) were able to conduct an entire four group study using one karate class and having the subjects interface except for each group's different training time. Thus, it appears feasible and justifiable to use one team as the subject pool. In fact, due to the PSEP's length and individualized nature, a single coach/researcher could be very beneficial for reliably 
presenting equal time of instruction to the different players and groups.

Instruments

During the second phase of the PSEP, questionnaires and follow-up interviews were used to gain information about each athlete. A questionnaire (Appendix C) was used to find out information about the athlete's "self-perception of strengths and weaknesses, situations handled easily and consistently, and situations that tend to cause the greatest difficulty" (Boutcher \& Rotella, 1987. p. 130). Seabourne, et al. (1985) used both a questionnaire and interview to assess subjects in a karate class using different packages. The questionnaire topics in. the karate study included "what situations were anxiety-producing to them, how they coped with stress, how they mentally prepared for their activity, their self-talk, concentration problems, and other mental and emotional facets of preparation" (p. 43). Furthermore, a post treatment questionnaire was given to the PSEP (Appendix L) and attention-control (Appendix M) groups. A 7-point Likert scale was used to collect answers to questions concerning the different treatments.

Performance testing was collected by having each subject shoot 20 continuous and 20 discontinuous (game like) free throws. Weinberg, et al. (1983) in their pilot study work found that there was a significant positive correlation 
between shooting 20 and 50 free throws ( $\underline{x}=90)$. Thus, shooting 20 or 50 free throws during testing gives similar results. Other studies have also used 20 free throws to assess performance (Gray \& Fernandez, 1989; Lobmeyer \& Wasserman, 1986; Wrisberg \& Anshel, 1989). Shooting discontinuous free throws was accomplished by having a group of three subjects shoot two free throws each. After one subject shot his two free throws, the entire group ran a 60 foot distance and then a new subject became the shooter.

This process of running and rotating shooters continued until each subject shot twice for a total of ten times. The researcher sat underneath the basket and monitored the shots by recording one point for a made attempt and a zero for a missed attempt. The process of collecting discontinuous free throws is a modified version of Gray and Fernandez's (1989) research. This form of discontinuous shooting is supported by Lobmeyer and Wasserman (1986) and Nideffer and Deckner (1970), who have indicated that there is a need to collect free throw measures that are conducted under similar game like conditions.

Shooting continuous free throws was accomplished by having each subject attempt 20 free throws at a basket. The researcher recorded the total number of made attempts.

Log books were used to monitor each subject's completion of homework assignments. These homework assignments, such as 
audio cassette tapes, have been used to help athletes learn performance enhancement techniques such as progressive relaxation and imagery (Crocker, 1989a; Crocker, 1989b; Hamilton \& Eremouw, 1985; Noe1, 1980; Ungerleider, 1985). Log books have been used in previous research to monitor whether or not subjects are completing homework assignments on a daily basis (Hughes, 1990; Kendall, et al., 1990; Seabourne, et al., 1984; Seabourne, et al., 1985). In these log books, players kept track of homework assignments, amount of time spent on homework, and any general comments that would be discussed during researcher led discussions.

Lastly, a video camera was used to tape each player's free throw shooting in order to isolate mechanical errors before and during the treatment (Rotella \& Boutcher, 1987). Procedures

The procedures of the study are categorized for each day of the treatment. The treatment lasted 5 weeks with the subjects meeting four times a week. Each session lasted approximately 15-20 minutes. Research has shown that short sessions can be more effective than a small number (five) of long ( 1 hour) sessions (Fenker \& Lambiotte, 1987; Smith, 1987). Furthermore, in order to increase compliance, sessions proceeded and followed team practice. Thus, the subjects did not have to change their schedule drastically during treatment. 
Both the PSEP group and the attention-control group followed the same procedures for days 1, 2, and 20 . Day 1 - Subjects were placed into one of two groups: pretest group and written test group. Subjects in the test taking group shot 20 continuous free throws at a basket with the number of total made shots and basket location recorded. Next, groups of three subjects placed themselves at one of the baskets for the discontinuous shooting test. One subject was at the free throw line while the other two were at each side of the free throw area. After the shooter attempted two free throws, all three subjects ran from one sideline to the other sideline, and back to the basket. After returning to the basket, a new shooter attempted two free throws. After the second shooter completed the two shots, all the subjects again ran from one sideline to the other sideline, and back to the basket. This process continued until a total of 20 shots were attempted by each subject. The researcher recorded how many baskets were made by each subject and which basket was used. Furthermore, a stationary video camera, monitored by the researcher, was used to tape each subject's free throw shot during the discontinuous shooting. The camera was positioned at a 45 degree angle from the player and the baseline under the basket.

Subjects in the written test group completed a questionnaire (Appendix C) that was used for subject 
assessment. After both groups were finished with their tasks, each group completed the other task.

Day 2 - Subjects were assigned to one of the two treatment groups by balancing the shooting skills of the two groups.

Subjects viewed a tape on proper free throw shooting principles made by the researcher (Appendix D). After the video, each subject and the members of their treatment group viered their own shooting. Mechanical errors in technique were explained to each subject with an individualized written list of errors to provide each subject guidance in correcting free throws shooting errors.

Also, assignments and the use of log books were discussed after viewing the video (Appendix E). The researcher stressed the importance of taking responsibility for each subject's own growth as a basketball player. Subjects were told that they need to be honest in their recording of homerork. It was stressed that the chances of improving as a basketball player will be increased if they did their homework. Furthermore, log book checks were conducted, and subjects were asked to bring their books to practice.

The PSEP group followed this procedure:

Day 3 - The group discussed how anxiety and porry can affect performance. The group also discussed why attention is important and why it is selective in nature. Furthermore, 
a discussion was led by the researcher on the need for commitment and the use of goal setting to increase commitment. Homework was to list three realistic goals to help improve free throw performance.

The control group followed this procedure:

Day 3 - The group discussed the importance of watching and reading about basketball to help cognitive development of basketball skills. The researcher assigned books to read as homework. Homework was to read for 20 minutes.

Days 4 through 19 are listed in Table 1 . Abbreviations used in the table are defined at the top of Table 1. 


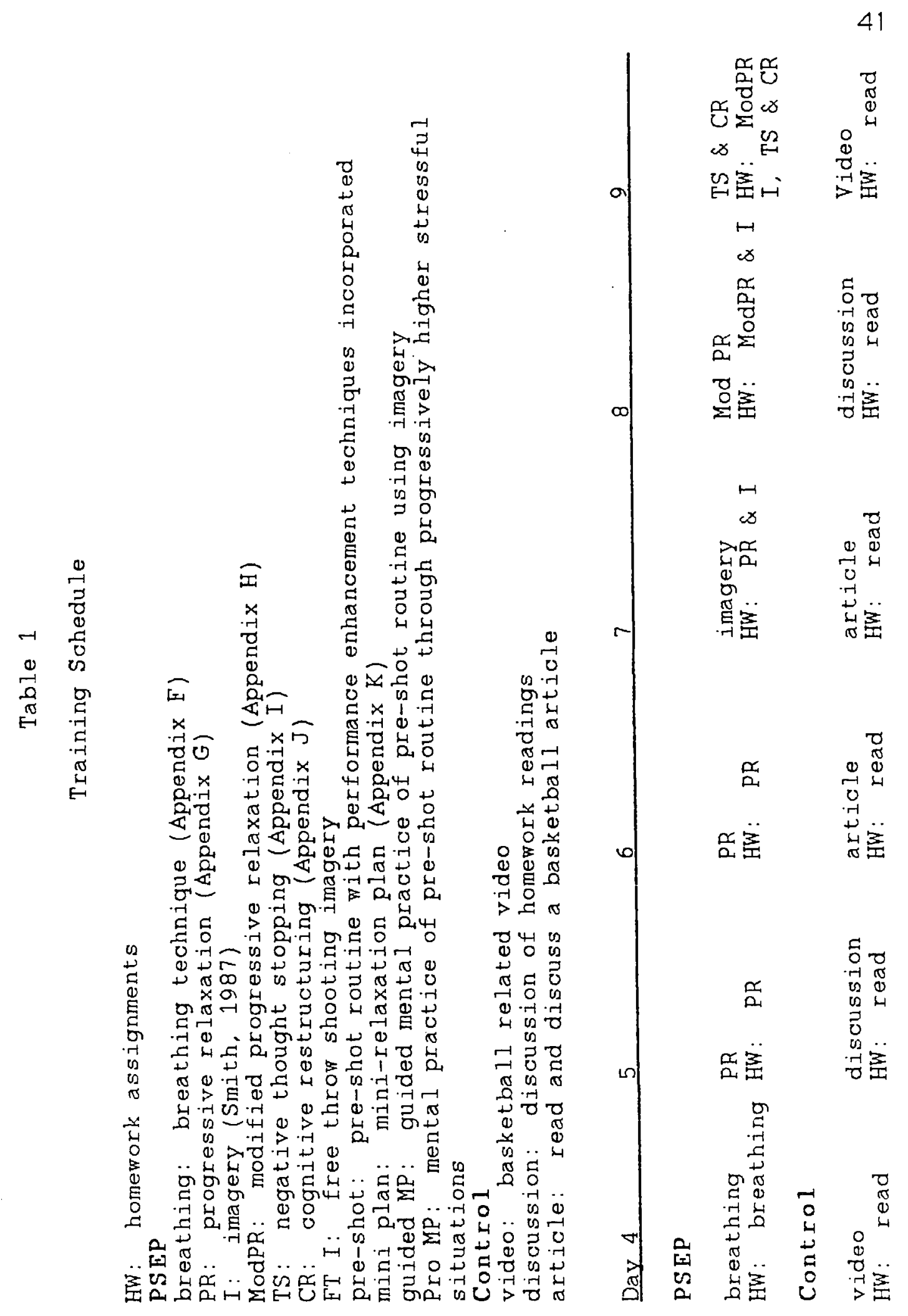




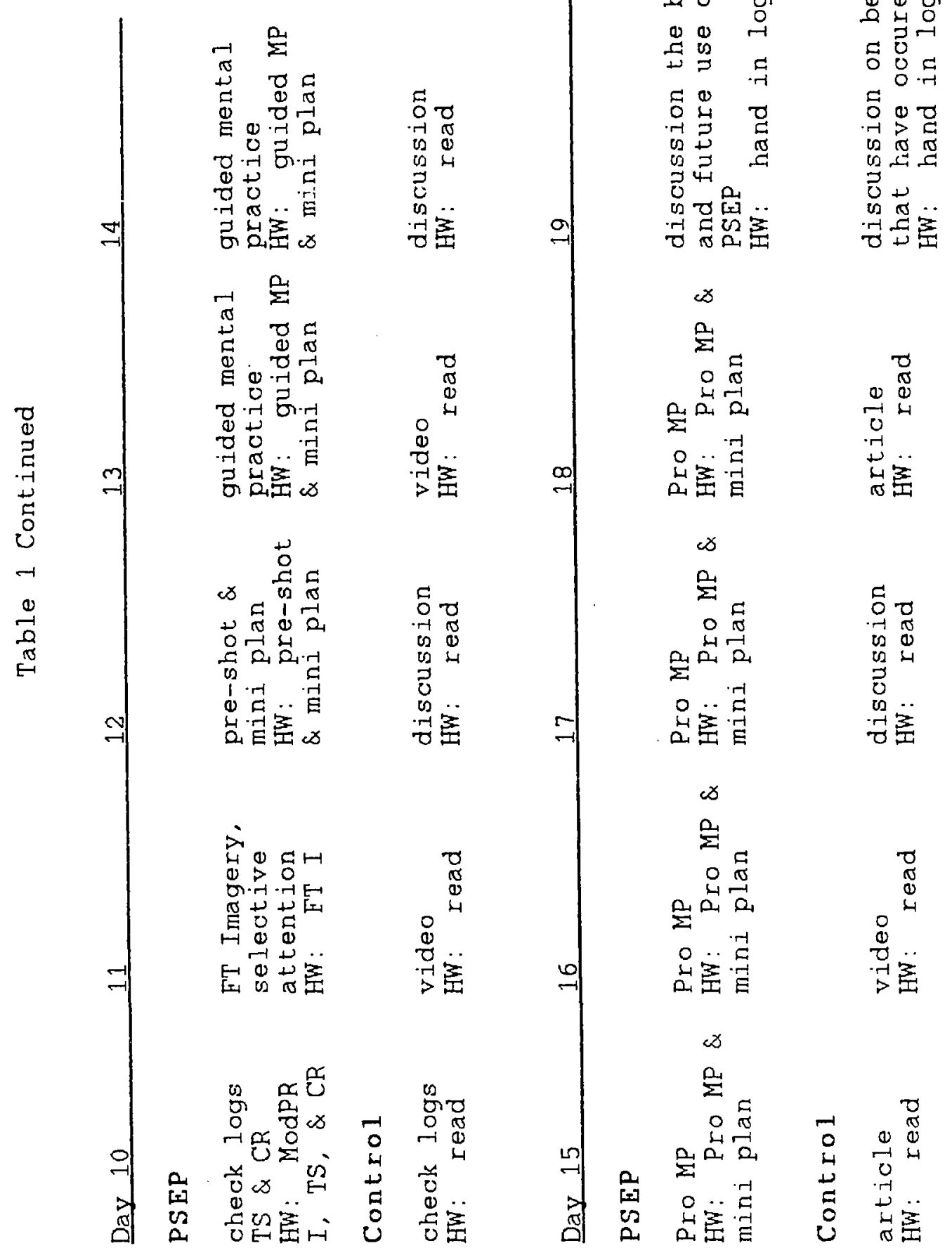


Both groups followed the same procedures for day 20 .

Day 20 - Post testing was completed by following the same procedures used on day 1 to collect free throw shooting scores. The written test group filled out a questionnaire that was tailored for their group (Appendix L \& M) .

Design

Testing on both continuous and discontinuous free throw performance was collected on the pre-test (day 1) and the post-test (day 20). The order of testing was counterbalanced across subjects. The treatment was completed during days 2 to 19. Subjects were assigned to either the PSEP or attention-control group. In order to insure that the PSEP and attention-placebo control groups were similar, a one way ANOVA was used on pre-test shooting scores.

Analysis

A one way ANOVA was used to determine differences between two types of shooting order, discontinuous/continuous and continuous/discontinuous. A two way ANOVA with repeated measures on the last factor was used to analyze the post-test scores. The two independent factors consisted of treatment group, PSEP and attention-control, and type of shooting, discontinuous and continuous

Post-test questionnaires for both the PSEP and attention-control were analyzed through descriptive statistics (Appendix $N \& 0$ ). 


\section{CHAPTER 4}

Results and Discussion

Results

A matched pairs design was used to place subjects into the PSEP and attention-control groups. The results of the pre-test analysis (Table 2) indicated that PSEP and attention-control group did not significantly differ in free throw shooting performance scores.

Table 2

Pre-test Means $(+1-$ SD) of Continuous and Discontinuous Free Throw Shooting Scores and ANOVA Information

\begin{tabular}{lll}
\hline & PSEP & Attention-control \\
\hline Continuous & $14.857(2.734)$ & $14.125(2.475)$ \\
Discontinuous & $12.714(3.861)$ & $12.000(4.375)$ \\
$\underline{E}(1,13)=.23$, MS $=3.91, \underline{D}>.05$ & \\
\hline
\end{tabular}

Thus, skill levels for both the PSEP group and the control group pere similar before any treatment.

Further analysis of pre-test results (Table 3) indicated that order of shooting, continuous/discontinuous and discontinuous/continuous, did not affect pre-test free throw shooting performance scores. 
Table 3

Pre-test Means ( $+1-$ SD) of Continuous and Discontinuous Eree Throw Shooting for Shooting Order (continuous/discontinuous or discontinuous/continuous) and ANOVA Information

\begin{tabular}{lll}
\hline & \multicolumn{1}{l}{ Dis/Con } & Con/Dis \\
\hline Continuous & $14.571(2.878)$ & $14.375(2.387)$ \\
Discontinuous & $11.857(3.579)$ & $12.750(4.559)$ \\
$\underline{E}(1,13)=.05$, MS $=0.91, \underline{p}>.05$ & \\
\hline
\end{tabular}

Regardless of whether subjects shot in the order of discontinuous/continuous or continuous/discontinuous, no difference in free throw performance was found. Because subjects were familiar with shooting free throws, a possible explanation for the results is that the task was not novel enough to show any order effect.

Analysis of pre-test results also indicated that continuous free throw shooting was more successful than discontinuous free throw shooting. Results collapsed over both treatment groups showed that continuous shooting $(\underline{M}=$ 14.467, $\underline{S D}=2.532$ ) was more successful than discontinuous shooting $(\underline{M}=12.333, \underline{S D}=4.012)$ during the pre-test, $\underline{E}(1,13)=5.09, \mathrm{MS}=34.00, \underline{\mathrm{p}}<.05$. Thus, subjects shot 
free throws significantly better when attempting continuous rather than discontinuous free throws.

After the pre-test, the PSEP group was taught mental training skills for 20 minutes a day for 5 weeks. Homework was also assigned to supplement group training. The attention-control group received general information on basketball for the same period of time as the PSEP group. The attention-control group was also assigned basketball related books to read on their own as homework assignments. After the 5 week treatment period, post-test scores were collected in the same manner as pre-test scores.

The results of the post-test analysis (Table 4) indicated that PSEP did not affect post-test free throw shooting performance scores.

Table 4

Post-test Means $(+1-$ SD) of Continuous and Discontinuous Free Throw Shooting Scores and ANOVA Information

\begin{tabular}{lll}
\hline & PSEP & Attention-control \\
\hline Continuous & $16.000(2.582)$ & $13.857(2.035)$ \\
Discontinuous & $12.286(2.812)$ & $12.000(3.162)$ \\
$\underline{E}(1.13)=.92, \mathrm{MS}=10.32, \underline{\mathrm{p}}>.05$ & \\
\hline
\end{tabular}


Therefore, PSEP training had no statistical effect on free throw shooting performance when compared to the attentioncontrol group.

Also, the results of the post-test analysis (Table 5) indicated that PSEP and type of shooting (continuous and discontinuous) did not affect post-test free throw shooting performance scores.

Table 5

Post-test ANOVA with Pairwise Comparisons for PSEP, Attention-control, Continuous, and Discontinuous Free Throw Shooting

\begin{tabular}{lll}
\hline & PSEP & Attention-control \\
\hline Continuous & $16.000(2.582)$ & $13.857(2.035)$ \\
Discontinuous & $12.286(2.812)$ & $12.000(3.162)$ \\
$\underline{E}(1,12)=1.90$, MS $=6.04, \mathrm{p}>.05$ & \\
\hline
\end{tabular}

Thus, there was no significant interaction between any of the pairwise comparisons on post-test scores.

Analysis of post-test results also indicated that the type of shooting was of statistical significance, $\underline{F}(1,13)=$ 17.09, $\mathrm{MS}=54.32, \underline{\mathrm{p}}<.05$, with continuous shooting $(\underline{\mathrm{M}}=$ 14.929, $\underline{\mathrm{SD}}=2.495$ ) showing greater success than 
discontinuous shooting $(\underline{M}=12.143, \underline{S D}=2.878)$. This result was similar to the results found during pre-test analysis. Discussion

The results indicate that for the male 14 and 15 year old basketball players in this study, there was no difference between the PSEP and attention-control groups. Thus, perhaps athletes similar to the subjects in this study do not need elaborate psychological plans for free throw shooting performance as created by the PSEP. Perhaps simple attention and general basketball knowledge are as important in free throw shooting as any elaborate psychological plan. For example, both the PSEP and the attention-control groups indicated on post-test questionnaires that their training was beneficial in shooting free throws (Appendix $\mathrm{N} \& 0$ ).

Furthermore, the subjects in this study might not have had the maturity level needed to show significant benefits from the PSEP. Perhaps, 14-15 year old male basketball players can not benefit from a psychological enhancement plan because they do not practice the techniques or they simply can not fully comprehend the techniques used in the PSEP.

Although the statistical results of this study indicate that the PSEP did not significantly affect subjects' free throw shooting, analysis of the post-test questionnaire (Appendix N) and informal interviews indicated that PSEP training was beneficial for the PSEP subjects. Analysis of a 
post-test questionnaire indicated that subjects in the PSEP group thought the training helped their free throw shooting. Furthermore, the PSEP group indicated that the training could be beneficial in other parts of their lives. For example, in informal researcher led interviews, subjects found the PSEP technique beneficial for taking academic tests and dealing With personal problems.

Informal interviews coupled with the survey results (Appendix N) revealed that the relaxation technique and entire pre-shot routine were the most effective techniques used in the training. Next, subjects stated that imagery and negative thought stopping were somewhat effective. Finally, subjects indicated that cognitive restructuring was only slightly effective. These results can be explained by analysis of each technique. First, both the relaxation technique and the pre-shot routine were presented in a form that did not take an extreme amount of mental concentration. For example, the relaxation technique ras placed on an audio cassette, so the subject had to only listen to the tape and follow the instructions. Also, the pre-shot routine was written down by each subject, so the only training needed was repetition through free throw shooting practice.

In contrast, imagery, negative thought stopping, and cognitive restructuring were introduced through discussion and homework lessons. It might be that these three 
techniques could not have been mastered without a good deal of thought and self-awareness. Perhaps the subjects found it difficult to visualize, and understand their own self-doubts without having a technique that led them through step by step. Thus, future research might use techniques that give step by step directions for imagery, negative thought stopping, and cognitive restructuring or designate more time in discussing these three techniques.

There are four reasons why the current study might not have found significant differences between the PSEP and attention-control groups. First, although previous research has used the discontinuous shooting task performed in this study, this discontinuous task might not be game-like enough to show any real differences in performance after completing the PSEP. Thus, the content validity of shooting free throws in an actual game in comparison to the free throw shooting accomplished in this study must be looked at critically. For example, one subject made 11 out of 20 attempts during the post discontinuous test. However, during an actual game a week earlier this subject made 10 out of 10 free throws. Furthermore, this subject indicated to the researcher in an informal interview that the PSEP had helped him accomplish this perfect score.

Secondly, all the subjects were fairly good free throw shooters, so 20 free throws in each type of shooting might 
not have been enough attempts to find any differences betreen groups even if differences existed. For example, a greater number of free throw attempts might be needed to show differences. Also, perhaps testing should have occurred over a longer period of time, for example, 2 or 3 days with repeated tests for discontinuous and continuous shooting, rather than collecting shooting scores on only one day.

Next, the PSEP subjects might not have practiced or used the techniques in the package to the extent that is needed to show positive results. For example, log books indicated that subjects in the PSEP group did not finish their assignments all the time even with encouragement from the researcher. Furthermore, on a post training survey, subjects in the PSEP group indicated that they only practiced the technique "some of the time." Previous research has shown that subjects need to practice on their own to complement any practice done during the actual training. Moreover, the researcher observed that some of the PSEP subjects showed obvious facial frustration when they missed shots during the post test. These subjects who became frustrated were not using any cognitive restructuring strategies during the test. Thus, perhaps if PSEP subjects had practiced their techniques more, it might have been easier to use the PSEP during the both competition and the post-test shooting. 
Another reason for the lack of significant difference between groups could be the small sample size. A small sample size can cause the statistical porer of the study to drop significantly. Therefore, significant results might have been lacking because more subjects were needed to increase the power of the study. However, because of the PSEP's long training period and individualized skills, researchers must try to increase the sample size without losing the PSEP's individualized training. In the current study, the small sample size was used because of the need to use one team for the study. By having all the subjects on one team, the researcher could control for the amount of physical practice and the amount of coach led discussion on free throw shooting. 


\section{CHAPTER 5}

\section{Conclusions and Recommendations}

Conclusions

Statistical results from this study indicate that in post-test free throw shooting there is no difference between PSEP and attention-control groups. The maturity level of the subjects might affect the degree of PSEP benefits.

Furthermore, individualized attention might give certain athletes significant confidence and motivation that is equal to the benefits from any psychological package. In fact, both the PSEP and attention-control groups in the current study indicated that their training was beneficial in free throw shooting performance (Appendix $N \& L$ ).

Although there were no significant group effects found between the PSEP and attention-control groups, subjects in the PSEP group indicated the training was beneficial for a variety of reasons. A post-test questionnaire (Appendix N), informal post-test interviews, and informal interviews during the training period all suggested that the PSEP was beneficial for the subjects with their free throw shooting and entire basketball playing. Moreover, subjects indicated that they used techniques learned during the PSEP training for taking tests and dealing with non-basketball related problems. 
Recommendations

If future researchers change a few elements of this study, results might be different. First, future research could use different methods of collecting shooting scores. For example, if a high school basketball team is used, preseason and regular season free throw shooting could be compared, with PSEP training being taught between the two seasons. Another example of modifying the method of collecting the shooting scores would be to use the same method as used in this study, but collect both the pre-test and post-test scores over a 2 or 3 day period. Thus, a more realistic score of shooting performance rould be attained, rather than a 1 day test.

Furthermore, future research should place emphasis on when the technique is introduced. In the current study, the training was introduced in the middle of the season. Perhaps either beginning the training during pre-season training or during the off-season would produce different results.

Also, future researchers might teach the PSEP technique to an entire team and compare these results with a team that does not use any form of mental training. By using an entire team, researchers will be able to emphasize PSEP training techniques during actual practice situations without fear of ruining the validity of the study. Thus, a researcher or 
coach could stop practice to discuss a PSEP technique that an athlete either forgot to use or did use.

Also, future research could study the differences betreen novice and experts who use PSEP training. This research could reveal the effectiveness of training subjects who are of different ages and skill levels using the PSEP. Results of this nature could indicate rhich techniques are most beneficial for each type of athlete and guidelines could produced to help both coaches and athletes.

Finally, researchers using PSEP training should allow for more time in their studies. In the current study, more time may have been needed to master each technique and allow each subject to feel comfortable with all the techniques. Only when subjects have mastered all the techniques can they truly decide which techniques will be most beneficial to increase their performance. 


\section{References}

Bird, A.M., \& Cripe, B.K. (1986). Psychology of sport behavior. St. Louis: Times Mirror/Mosby.

Boutcher, S.H., \& Crews, D.J. (1987). The effect of a preshot attentional routine on a well-learned skill. International Journal of Sport Psychology, 18, 30-39.

Boutcher, S.H., \& Rotella, R.J. (1987). A psychological skills educational program for closed-skill performance enhancement. The Sport Psychologist, 1 127-137.

Clark, L.V. (1960). Effect of mental practice on the development of a certain motor skill. The Research Quarterly, 31, 560-569.

Cohn, P.R., Rotella, R.J., \& Lloyd, J.W. (1990). Effects of a cognitive-behavioral intervention on the preshot routine and performance in golf. The Sport Psychologist, 4. 33-47.

Cox, R.H. (1990). Sport psychology: Concepts and applications (2nd ed.). Dubuque, IA: Wm. C. Brown.

Crews, D.J., \& Boutcher, S.H. (1986). Effects of structured preshot behaviors on beginning golf performance. Perceptual and Motor Skills, 62, 291-294.

Crocker, P.R. (1989a). A follow-up of cognitive-affective Stress Management Training. Journal of Sport \& Exercise Psychology, 11, 236-242. 
Crocker, P.R. (1989b). Evaluating Stress Management Training under competition conditions. International Journal of Sport Psychology, 20, 191-204.

Crocker, P.R., Alderman, R.B., \& Smith, F.M. (1988).

Cognitive-affective Stress Management Training with high performance youth volleyball players: Effects on affect, cognition, and performance. Journal of Sport \& Exercise Psychology, 10, 448-460.

Eeltz, D.I., \& Landers, D.M. (1983). The effects of mental practice on motor skill learning and performance: A metaanalysis. Journal of Sport Psychology, $\underline{5}$, 25-57.

Fenker, R.M., \& Lambiotte, J.G. (1987). A performance enhancement program for a college football team: One incredible season. The Sport Psychologist, 1, 224-236.

Gauron E.F (1986). The art of cognitive self-regulation. Clinics in Sport Medicine, 5, 91-101.

Gayton, W.E., Cielinski, K.L., Francis-Keniston, W.J., \& Hearns, J.E.(1989). Effects of preshot routine on freethrow shooting. Perceptual and Motor Skills, 68, 317-318.

Girdano, D.A., \& Everly, G.S. (1986). Controlling stress and tension: a holistic approach. Englewood Cliffs, $\mathrm{NJ}$ : Prentice-Hall.

Gould, D. (1986). Goal setting for peak performance. In J.M. Williams (Ed.), Applied sport psychology (pp. 133-147). Palo Alto, CA: Mayfield. 
Gray, S.W., \& Fernandez, S.J. (1989). Effects of Visuo-Motor Behavior Rehearsal with videotaped modeling on basketball shooting performance. Psychology, A Journal of Human Behavior, $26,41-47$.

Greenberg, J.S. (1987). Comprehensive stress management (2nd ed.). Dubuque, IA: Wm. C. Brown.

Greenspan, M.J., \& Feltz, D.L. (1989). Psychological interventions with athletes in competitive situations: A review. The Sport Psychologist 3 , 219-236.

Greider, P.C. (1991). The pre-free throw ritual. Scholastic Coach, $\underline{60}, 44,46$.

Hale, B.D. (1982). The effects of internal and external imagery on muscular and ocular concomitants. Journal of Sport Psychology, 4 , 379-387.

Hall, E.G., \& Erffmeyer, E.S. (1983). The effect of VisuoMotor Behavior Rehearsal with videotaped modeling on free throw accuracy of intercollegiate female basketball players. Journal of Sport Psychology, 5, 343-346.

Hamilton, S.A., \& Fremouw, W.J. (1985). Cognitive-behavioral training for college basketball free-throw performance. Cognitive Therapy and Research, 9 479-483.

Harris, D.V., \& Robinson, W.J. (1986). The effects of skill level on EMG activity during internal and external imagery. Journal of Sport Psychology, $105-111$. 
Hughes, S. (1990). Implementing psychological skills

training program in high school athletics. Journal of Sport Behavior, 13, 15-22.

Kendall, G., Hrycaiko, D., Martin, G.L., \& Kendall, T.

(1990). The effects of an imagery, rehearsal, relaxation, and self-talk package on basketball game performance. Journal of Sport \& Exercise Psychology, 12, 157-166.

Lanning, W. \& Hisanaga, B. (1983). A study of the relation between the reduction of competition anxiety and an increase in athletic performance. International Journal of Sport Psychology, 14, 219-227.

Lobmeyer, D.L., \& Wasserman, E.A. (1986). Preliminaries to free throw shooting: Superstitious behavior? Journal of Sport Behavior, $9,70-78$.

Mace, R.D., \& Carroll, D. (1989). The effect of Stress Inoculation Training on self-reported stress, observer's rating of stress, heart rate and gymnastics performance. Journal of Sports Sciences, I, 257-266.

McAuley, E.. \& Rotella, R. (1982). A cognitive behavioral approach to enhancing gymnastic performance. Motor Skills: Theory into Practice, 67-75.

Meichenbaum, D.H., \& Deffenbacher, J.L. (1988). Stress Inoculation Training. The Counseling Psychologist, 16 $69-90$. 
Meyers, A.W., \& Schleser, R. (1980). A cognitive behavioral intervention for improving basketball performance. Journal of Sport Psychology, 2 69-73.

Meyers, A.W., Scheleser, R., \& Okwumabua, T.M. (1982). A cognitive behavioral intervention for improving basketball performance. Research Quarterly for Exercise and Sport, 53. $344-347$.

Murphy, S.M., \& Woolfolk, R.L. (1987). The effects of cognitive interventions on competitive anxiety and performance on a fine motor skill accuracy task. International Journal of Sport Psychology, 18, 152-166.

Nideffer, R.M., \& Deckner, C.W. (1970). A case study of improved athletic performance following use of relaxation procedures. Perceptual and Motor Skills, 30, 821-822.

Noel, R.C. (1980). The effect of Visuo-Motor Behavior Rehearsal on tennis performance. Journal of Sport Psychology, 2, 221-226.

Onestak, D.M. (1992). The effects of progressive relaxation, mental practice, and hypnosis on athletic performance: A review. Journal of Sport Behavior, 14, 247-282.

Schmidt, R.A. (1988). Motor control and learning (2nd ed.). Champaign, IL: Human Kinetics. 
Seabourne, T., Weinberg, R., \& Jackson, A. (1984), Effect of individualized practice and training of Visuo-Motor Behavior Rehearsal in enhancing karate performance. Journal of Sport Behavior I 58-67.

Seabourne, T.G., Weinberg, R.S., Jackson, A., \& Suinn, R.M. (1985). Effect of individualized, nonindividualized, and package intervention on karate performance: Journal of Sport Psychology I 40-50.

Smith, D. (1987). Conditions that facilitate the development of sport imagery training. The Sport Psychologist, 1 , $237-247$.

Suinn, R.M. (1976, July). Body thinking: Psychology for Olympic champs. Psychology Today pp. 38-43.

Ungerleider, S. (1985). Training for the Olympic games with mind and body: Two cases. Perceptual and Motor Skills, 61, 1291-1294.

Weinberg, R.S., Chan, R., \& Jackson, A. (1983). Mental preparation strategies and performance: Is a combination of techniques better than a single technique? Journal of Sports Sciences, 1 , 211-216.

Weinberg, R.S., Seabourne, T.G., \& Jackson, A. (1981). Effects of Visuo-Motor Behavior Rehearsal, relaxation, and imagery on karate performance. Journal of Sport Psychology, 3, 228-238. 
Wrisberg, C.A., \& Anshel, M.H. (1989). The effect of cognitive strategies on the free throw shooting performance of young athletes. The Sport Psychologist, 3 , $95-104$.

Wrisberg, C.A., \& Pein, R.L. (1992). The preshot interval and free throw shooting accuracy: An exploratory investigation. The Sport Psychologist 6 , 14-23.

Ziegler, S.G. (1987). Comparison of imagery styles and past experience in skills performance. Perceptual and Motor Skills, 64 , 579-586.

Ziegler, S.G., Klinzing, J., \& Williamson, K. (1982). The effects of two stress management training programs on cardiorespiratory efficiency. Journal of Sport Psychology, 4, 280-289. 


\section{Appendix A \\ Pre-shot Routine}

1. Say a positive phrase of think a positive thought.

2. Imagine the ball going in before you shoot.

3. Position your feet exactly the same way each time.

4. Physically rehearse the stroke.

5. Bend or bounce your knees.

6. Dribble the ball.

7. A breathing sequence, including a least one deep

exhalation to help you relax.

8. A visual sequence that determines precisely wat you

look at from the time the referee gives you the ball until it

goes through the net.

9. Block out external sounds.

10. Hold the ball the same way each time.

11. A pre-release position that remains the same every time, including the position of the elbow, hand, etc.

12. A certain follow through position.

13. Physical sensations that correspond with successful shots.

(Greider, 1991) 
Appendix B

Consent Form

Responsible Investigator: Rob Wojtkowski

Title of Protocol: The Effects of the Psychological Skills Educational Program (PSEP) on Free Throw Shooting for Male High School Basketball Players

Your child has been asked to participate in a research study investigating how to improve free throw shooting. Your child will be asked to learn about general basketball knowledge and techniques such as relaxation, imagery, and techniques to stop negative thinking. The study will occur during the January and February of 1993. The study will use the gym at Leigh High School. Furthermore, practice assignments will be given to the subjects to be finished at their leisure. There are no risks anticipated for your son. Your son may potentially benefit from this research by increasing his knowledge of basketball and learning stress reduction techniques. The results of this study may be published but no information that could identify an individual participant will be included.

Any questions concerning the research can be addressed to Rob Wojtkowski (408-378-8327), or my graduate advisor David Furst, Ph.D., at 924-3039. Complaints about the research may be presented to James Bryant, Ph.D., Department Chair for the Department of Human Performance, at (408) 924- 
3010. Questions or complaints aboutresearch, subjects'

rights, or research-related injury may be presented to Serena Stanford, Ph.D., Associate Academic Vice President for

Graduate Studies and Research, at (408) 924-2480.

Participation by your son is strictly voluntarily. Your son may refuse to participate in any part of the study. If your son decides to participate in the study, he or she is free to withdraw at any time without prejudice to your son's relations with his basketball team, the researcher. San Jose State University or any other participating institution. Each player will receive a signed and dated copy of the consent form.

Your signature on this document indicates agreement to allow your son to participate in the study.

Your son's signature indicates his willingness to participate in the study.

The signature of a researcher on this document indicates agreement to include the above named subject in the research and attestation that the subject has been fully informed of his rights.

\begin{tabular}{ll}
\hline Subject's Signature & $\overline{\text { Date }}$ \\
$\overline{\text { Parent's Signature }}$ & $\overline{\text { Date }}$ \\
$\overline{\text { Investigator's Signature }}$ & $\overline{\text { Date }}$
\end{tabular}




\section{Appendix C \\ Pre-test Questionnaire}

Name :

Please answer the following questions as truthfully as possible. Your answers will be kept confidential. All answers will be in reference to free throw shooting.

1) When shooting free throws, what type of situations do you handle both easily and consistently?

2) When shooting free throws, what type of situations are more difficult for you?

3) How do you cope with anxiety at the free throw line?

4) What is your mental preparation before you shoot a free throw?

5) Do you find yourself talking "mentally" to yourself? If yes, what do you commonly say to yourself in different situations?

6) Do you find yourself not concentrating at the free throw lines at times? If yes, why do you think you have difficulties in concentrating? 


\section{Appendix D \\ Shooting Video}

1) Place your feet the same way every time (shooting foot slightly formard).

2) Relax your knees and have a slight knee bend.

3) Hold the ball in your shooting hand with your wrist bent at the point when wrinkles are seen in your wrist. Have your shooting elbow make a " $L$."

4) Place your off hand on the side of the ball.

5) Allow your finger pads to touch the ball and have no contact with the center of your palm. Fingers should be relaxed and spread in a comfortable fashion. The distance between your shooting thumb and index finger should not be extremely large.

6) Hold the ball in a relaxed position in front of your body .

7) Look through both eyes evenly and pick a spot on the basket that you will watch throughout your shot.

8) Begin the shooting motion by "pushing your toes into the ground," allowing your arm to extend, and your shooting wrist to follow through. Your shooting hand should have your middle finger "go up and over the front of the rim" for a proper arc and follow through. 
9) After releasing the ball, make sure you hold your follow through and have your off-hand just below the wrist of your shooting hand. 
Appendix E

Log Book

Name:

Please record the date, start and ending time, and what you did for homework. Include any comments that you would like to bring up in discussions.

Date:

Date:

Start:

Finish:

Start: Finish:

Homework?

Homework?

Comments:

Comments:

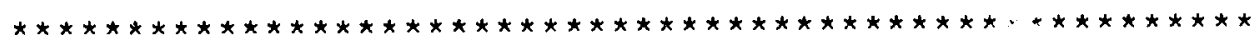

Date:

Date:

Start:

Finish:

Start: Finish:

Homework?

Homework?

Comments:

Comments:

\begin{tabular}{|c|c|c|c|}
\hline Date: & \multirow{3}{*}{ Finish: } & \multicolumn{2}{|l|}{ Date: } \\
\hline Start: & & Start: & Finish \\
\hline Homework? & & Homewo. & \\
\hline Comments: & & Commen & \\
\hline
\end{tabular}




\section{Appendix $\mathrm{F}$ \\ Breathing Technique}

Step 1. Assume a comfortable position. Rest your left hand (palm down) on top of your abdomen. More specifically, place your left hand over the top of your navel. Now place your right hand so that it comfortably rests on your left. Your eyes should remain open.

Step 2. Imagine a hollow bottle or pouch lying internally beneath the point at which your hands are resting. Begin to inhale. As you inhale, imagine that the air is entering through your nose and descending to fill that internal pouch. Your hands will rise as you fill the pouch with air. As you continue to inhale, imagine the pouch being filled to the top. your rib cage and upper chest will continue the wavelike rise that was begun at your navel. The total length of your inhalation should be 3 seconds for the first week or so, then lengthening to 4 to 5 seconds as you progress in skill development.

Step 3. Slowly begin to exhale--to empty the pouch. As you do, repeat to yourself the word "RELAX." As you exhale, you will feel your raised abdomen and chest recede.

Repeat this exercise two times in succession.

(Girdano \& Everly, 1986) 
Appendix G

Progressive Relaxation

Relaxation of the arms (four or five minutes)

Settle back as comfortably as you can and let yourself relax to the best of your ability.

Now, as you relax, clench your right fist.

Clench it tighter and tighter, and study the tension as you

do so.

Keep it clenched and feel the tension as you do so.

Now relax. . .

Let the fingers of your right hand become loose.

Observe the contrast in your feelings.

Now, let yourself go and try to become more relaxed all over.

Once more, clench your right fist really tight.

Hold it, and notice the tension again.

Now, let go, relax, let your fingers straighten out.. .

Notice the difference once more.

Now repeat that with your left fist.

Clench your left fist while the rest of your body relaxes.

Clench that fist tighter and feel the tension.

And now relax.. Again, enjoy the contrast.

Repeated that once more, clench the left fist, tight and

tense.

Now do the opposite of tension -- Relax and feel the

difference.

Continue relaxing like that for awhile.

Clench both fists tighter and tighter, both fists tense, forearms tense.

Study the sensations. . and relax...

Straighten out your fingers and feel that relaxation.. .

Continue relaxing your hands and forearms more and more.

Now bend your elbows and tense your biceps.

Tense them harder and study the tension feeling.

All right, straighten out your arms.

Let them relax and feel the difference again.

Let the relaxation develop.

Once more, tense your biceps.

Hold the tension and observe it carefully.

Straighten the arms and relax.. .

Relax to the best of your ability. .

Each time pay close attention to your feelings when you tense up and when you relax. 
Now straighten your arms, straighten them so that you feel most tension in the triceps muscles along the back of your arms.

Stretch your arms and feel the tension.

And now relax. .

Get your arms back into a comfortable position. .

Let the relaxation proceed on its own. . .

The arms should feel comfortably heavy as you allow then to

relax. the triceps muscles.

Feel than tension. . and relax.

Now let's concentrate on pure relaxation in the arms without

any tension. corfortable and let them relax further and

further. .

Continue relaxing your arms even further. . .

Even when your arms seem fully relaxed, try to go that extra

bit further

Try to achieve deeper and deeper levels of relaxation.

Relaxation of the face, neck, shoulders, and upper back (four of five minutes)

Let all your muscles go loose and heavy.

Just settle back quietly and comfortably.

Wrinkle up your forehead now, wrinkle it tighter.

And now stop wrinkling up your forehead.

Relax and smooth it out. .

Picture the entire forehead and scalp becoming smoother, as

the relaxation increases.

Now frown and crease your brows and study the tension.

Let go of the tension again...

Smooth out the forehead once more.

Now, close your eyes.

Keep your eyes close, gently, comfortably, and notice the

relaxation.

Now clench your jaws, push your teeth together.

Study the tension throughout the jaws.

Relax your jaws now...

Let your lips part slightly

Appreciate the relaxation.

Now press your tongue hard against the roof of your mouth.

Look for the tension.

All right, let your tongue return to a comfortable and

relaxed position. tighter.

Relax the lips.. . 
Notice the contrast between tension and relaxation... Feel the relaxation all over your face, all over your forehead, and scalp, eyes, jaws, lips, tongue, and throat. . The relaxation progresses further and further.

Now attend to your neck muscles.

Press your head back as far as it can go and feel the tension in the neck.

Roll it to the right and feel the tension shift. . .

Now roll it to the left.

Straighten your head and bring it forward.

Press your chin against your chest.

Let your head return to a comfortable position and study the relaxation. .

Let the relaxation develop.

Shrug your shoulders right up.

Hold the tension.

Drop your shoulders and feel the relaxation. . .

Neck and shoulders relaxed.

Shrug your shoulders again and move them around.

Bring your shoulders up and formard and back.

Feel the tension in your shoulders and in your upper back $/$

Drop your shoulders once more and relax..

- Let the relaxation spread deep into the shoulders right into your back muscles.

Relax your neck and throat, and your jaws and other facial areas, as the pure relaxation takes over and grows deeper. deeper. . even deeper.

Relaxation of the chest, stomach, and lower back (four or five minutesl

Relax your entire body to the best of your ability.

Feel that comfortable heaviness that accompanies relaxation.

Breathe easily and freely in and out. . .

Notice how the relaxation increases as you exhale. . .

As you breathe out, just feel that relaxation.

Now breathe right in and fill your lungs.

Inhale deeply and hold your breath.

Study the tension.

Now exhale, let the walls of your chest grow loose, and push the air out automatically.

Continue relaxing and breathe freely and gently.

Feel the relaxation and enjoy it.

With the rest of your body as relaxed as possible, fill your lungs again.

Breath in deeply and hold it again. 
Now breathe out and appreciate the relief, just breathe normally. . Continue relaxing your chest and let the relaxation spread to your back, shoulders, neck and arms... .

Merely let go and enjoy the relaxation.

Now let's pay attention to your abdominal muscles, your stomach area.

Tighten your stomach muscles, make your abdomen hard.

Notice the tension.

And relax, let the muscles loosen and notice the contrast.

Once more, press and tighten your stomach muscles.

Hold the tension and study it.

And relax, notice the general well-being that comes with relaxing your stomach.

Now draw your stomach in.

Pull the muscles right in and feel the tension this way.

Now relax again. . . Let your stomach out...

Continue breathing normally and easily and feel the gentle massaging action all over your chest and stomach.

Now pull your stomach in again and hold the tension.

Once more pull in and feel the tension.

Now relax your stomach fully

Let the tension dissolve as the relaxation grows deeper.

Each time you breather out, notice the rhythmic relaxation both in your lungs and in your stomach. .

Notice how your chest and your stomach relax more and more.

Try to let go of all contractions anywhere in your body.

Now direct your attention to your lower back.

Arch up your back, make your lower back quite hollow, and feel the tension along your spine.

Now settle down comfortably again, relaxing the lower back. Just arch your back up and feel the tensions as you do so.

Try to keep the rest of your body as relaxed as possible.

Try to localize the tension throughout your lower back area.

Relax once more, relaxing further and further...

Relax your lower back, relax your upper back, spread the

relaxation to your stomach, chest, shoulders, arms and facial

area.

These parts relaxing further and further and further and even deeper.

Relaxation of the hips, thighs, and calves four or five minutes)

Let go of all tensions and relax. Now flex your buttocks and thighs. 
Flex your thighs by pressing down your heels as hard as you can.

Relax and notice the difference.

Straighten your knees and flex your thigh muscles again.

Hold the tension.

Relax your hips and thighs... .

Allow the relaxation to proceed on its own.

Press your feet and toes downwards, away from your face, so

that your calf muscles become tense.

Study that tension.

Relax your feet and calves.

This time, bend your feet towards your face so that you feel tension along your shins.

Bring your toes right up.

Relax again. . Keep relaxing for awhile. .

Now let yourself relax further all over. .

Relax your feet, ankles, calves and shins, knees, thighs, buttocks and hips.

Feel the heaviness of your lower body as you relax still further.

Now spread the relaxation to your stomach, waist and lower back.

Let go more and more deeply. . .

Make sure no tension has crept into your throat.

Relax your neck and your jaws and all your facial muscles.

Keep relaxing your whole body like that for awhile. . .

Let yourself relax.

Now you can become twice as relaxed as you are by merely

taking in a really deep breath and slowly exhaling. with your

eyes closed. so that you become less aware of objects and

movements around you, and thus prevent and surface tensions

from developing.

Breathe in deeply and feel yourself becoming heavier.

Take in a long, deep breath and exhale very slowly. . .

Feel how heavy and relaxed you have become.

In a state of perfect relaxation, you should feel unwilling to move a single muscle in your body.

Think about the effort that would be required to raise your right arm.

As you think about that, see if you can notice any tensions

that might have crept into your shoulders and arm,

Now you decide not to lift the arm, but to continue relaxing

Observe the relief and the disappearance of the tension.

Just carry on, relaxing like that. . . Continue relaxing.

When you wish to get up, count backwards from four to one.

You should now feel fine and refreshed, wide awake and calm.

(Greenberg, 1987) 
Appendix $\mathrm{H}$

Modified Progressive Relaxation

There may be occasions when you choose not to devote as much time to relaxation as the exercises just presented require. In those instances, you can still practice a modified, simplified, and quick version of progressive relaxation. For example, you may be working at your desk and notice that your shoulder muscles are tense. To relax them you can tense them further--raising your shoulders as high as you can get them--and then let them relax. Focus on the sensations of your relaxed shoulder muscles, paying particular attention to any warm and tingly sensations.

Another quick exercise you can do involves your abdominal muscles. Make these muscles tense by keeping your abdominal area flat but tight. Notice how you breathe with these muscles tensed--with the expansion of your chest muscles alone. Be aware of the sensations of breathing this way. Now relax your abdominal muscles and let your abdominal area stick out. Breathe by the expansion and contradiction of your abdominal area rather than your chest. To help breathe this way, place the palm of your hand on your abdomen. Let your hand rise and fall as your abdomen rises when you inhale and falls when you exhale. Notice how relaxed you feel breathing in this manner. 
You can improvise your orn quick, modified version of progressive relaxation by identifying any particular muscle group that feels tense and then tensing it further. Next, relax that muscle group and focus upon the feelings of relaxation. After approximately five minutes of such an exercise, you can begin to feel less tense and more relaxed-and better able to proceed with the rest of your day. You might even do such exercises on schedule each day, considering that five minutes as a "vacation period" in which you leave your daily cares to travel to a more relaxed state.

(Greenberg, 1987) 
Appendix I

Thought Stopping

Bring up a Thought. Close your eyes and bring into your imagination a situation in which some unwanted or detrimental thought is likely to occur. Try to include normal as well as obsessive thinking. In this way you can learn to interrupt stressful thoughts while allowing a continuing flow of healthy thinking. Your first step in this exercise is to conjure up a particular line of thinking that you want to interrupt.

Unaided Thought Stopping. . . While Ruminating on the unwanted thought, shout "Stop!" When you succeed in extinguishing the thought on several occasions with the shouted command, begin interrupting the thought with "Stop!" said in a normal voice. After succeeding in stopping the thought by using your normal speaking voice, start interrupting the thought with "Stop" verbalized in a whisper. When the whisper is sufficient to interrupt stressful thoughts, use a subvocal command, "Stop." Imagine hearting "Stop!" shouted inside your mind. Tighten your vocal cords and move your tongue as if you were saying "Stop!" out loud. Success as this stage means that you can stop your thoughts alone or in public without making a sound or without calling attention to yourself. 
Thought Substitution. The last phase of thought stopping involves thought substitution. In place of the unwanted thought, make up another thought, perhaps a positive or assertive statement that is more appropriate in the target situation. For example, if you are afraid of flying, you might say to yourself. "I like to fly. I particularly enjoy the fantastically beautiful view from way up in the air." Develop several alternative assertive statements to think instead of the one you want replaced, Because one new response may lose its power through repetition. Continue to practice the entire sequence of first interrupting the thought and then substituting an alternative thought in its place.

(Gauron, 1986) 


\section{Appendix J}

\section{Cognitive Restructuring}

Perspective makes all the difference in cognitive restructuring. A change of perspective or a different way of looking at things gives new meaning to the same event. The skill to be cultivated is the art of cognitive flexibility, to be able to change cognitions or meaning attributions as often as is necessary, especially when it is personally advantageous to do so. Carry out this simple training exercise now.

Some general guidelines are pertinent to this exercise: A disadvantage may be transformed into an advantage. A disaster may be transformed into a development. A threat may transform into a challenge. An end may transformed into a beginning.

$\begin{array}{ll}\text { Disadvantage } & ------ \text { Advantage } \\ \text { Disaster } & ------- \text { Development } \\ \text { Threat } & ------ \text { Challenge } \\ \text { End } & \text {------- Beginning }\end{array}$

Making use of the left-hand column, reflect on recent personal experiences. Pick an instance of each in turn that has occurred within the last 2 weeks in your personal life: a disadvantage, a disaster, a threat, and an end. While thinking about these events, reconceptualize each in such a way that it becomes an element in the right-hand column: an 
advantage, an development, a challenge, and a beginning, respectively. Practice this as often as is necessary until you become skillful with this technique.

For a second practice assignment, pick 10 events from the past, events that you have interpreted to this point as disadvantages. Your task now is to reconceptualize each happening so that it can be conceived of as an advantage. It is surprising to see how many so-called negative experiences can be neutralized or even turned into positive experiences.

(Gauron, 1986) 


\section{Appendix K \\ Mini-relaxation Plan}

1. In a quiet room and in a comfortable chair, assume a restful position and a quiet, passive attitude. Take four deep breathes. Make each one deeper than the one before: Hold the first inhalation for 4 seconds, the second one for 5 seconds, the third one for 6 seconds, the fourth one for 7 seconds. Pull the tension from all parts of your body into your lungs and exhale it with each expiration. Feel more relaxed with each breath.

2. Count backward from 10 to 0 . Breath naturally, and with each exhalation count one number and feel more and more relaxed as you approach 0 . With each count you descend a relaxation stairway and become more deeply relaxed until you are totally relaxed at 0 .

3. Now go to.. (a relaxing scene from the past that you create in your mind). . . stay there for four minutes. Try to vividly, but passively, recall the feelings of that place and time that were very relaxing.

4. Bring your attention back to yourself. Count from 0 to 10. Energize your body. Feel the energy, vitality, and health flow through your system. Feel alert and eager to resume your activities. Open your eyes.

(Girdano \& Everly, 1986) 


\section{Appendix L \\ PSEP Post Questionnaire}

Name :

Please answer these questions as truthfully as possible by marking the appropriate number.

$$
\text { not much slightly somewhat very }
$$

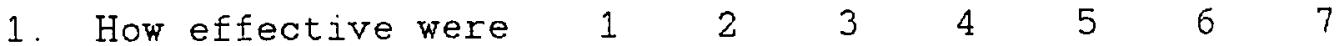
you in shooting free throws

before training?

2. How effective were $\begin{array}{llllllll}1 & 2 & 3 & 4 & 5 & 6 & 7\end{array}$ you in shooting free throws

after training?

3. How effective was each of these techniques for you:

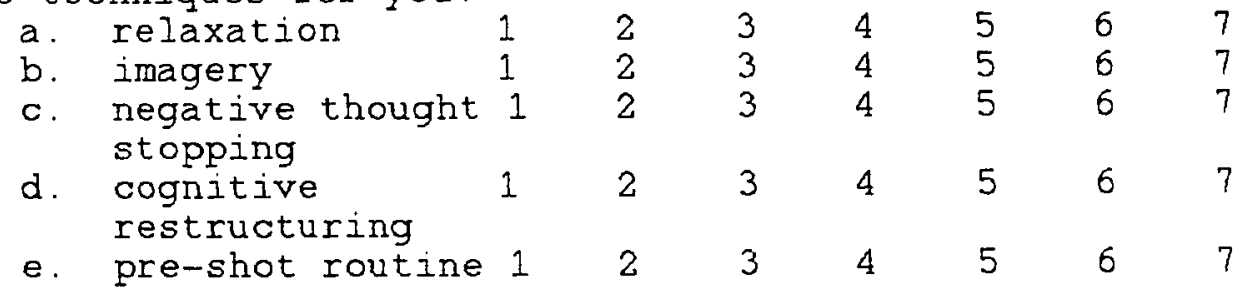

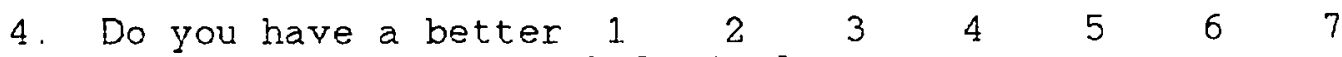
understanding of the psychological factors that can hinder shooting?

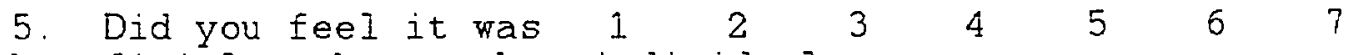
beneficial to hear other individuals talk about their experiences?

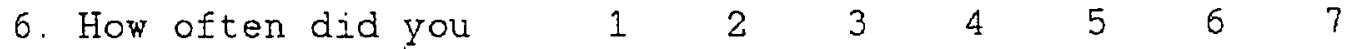
practice strategies/techniques used in the PSEP?

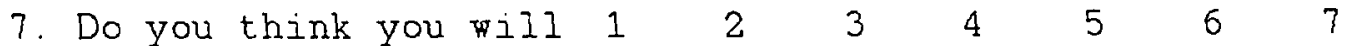
be able to use PSEP strategies in other parts of your basketball playing or in life? Explain:

Comments : 
Appendix $M$

Control Post Ouestionnaire

Name:

Please answer these questions as truthfully as possible by marking the appropriate number.

$$
\text { not much sightly somewhat very }
$$

1. How effective were $1 \begin{array}{lllllll}2 & 3 & 4 & 5 & 6 & 7\end{array}$

you in shooting free throws

before training?

2. How effective were $1 \begin{array}{llllllll} & 2 & 3 & 4 & 5 & 6 & 7\end{array}$ you in shooting free throws after training?

Corments: 
Appendix $\mathrm{N}$

PSEP Post Ouestionnaire Results

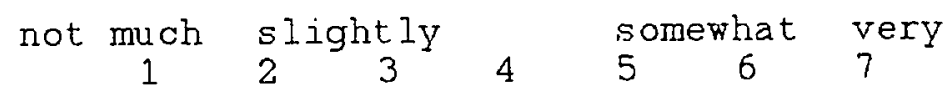

1. How effective were $\begin{array}{lllllll}0 & 0 & 2 & 1 & 2 & 2 & 0\end{array}$

you in shooting free throws

before training?

2. How effective were $\begin{array}{lllllll}1 & 0 & 0 & 0 & 5 & 1\end{array}$

you in shooting free throws

after training?

3. How effective was each of these techniques for you:

$\begin{array}{llllllll}\text { a. relaxation } & 0 & 0 & 1 & 1 & 0 & 2 & 3 \\ \text { b. imagery } & 1 & 0 & 0 & 0 & 3 & 2 & 1 \\ \text { c. negative thought } & 0 & 0 & 2 & 1 & 2 & 2 & 0 \\ \begin{array}{l}\text { stopping } \\ \text { dognitive }\end{array} & 2 & 3 & 0 & 2 & 0 & 0 & 0 \\ \quad \begin{array}{l}\text { restructuring } \\ \text { pre-shot routine }\end{array} & 1 & 0 & 1 & 0 & 0 & 1 & 4 \\ \text { Do you have a better } 0 & 0 & 0 & 0 & 2 & 2 & 3\end{array}$

4. Do you have a better $0 \quad 0 \quad 0 \begin{array}{lllll}0 & 0 & 2 & 2 & 3\end{array}$ understanding of the psychological factors that can hinder shooting?

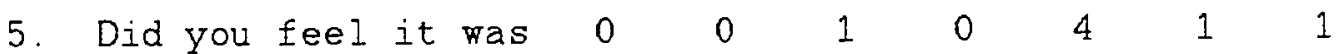
beneficial to hear other individuals

talk about their experiences?

6. How often did you $\quad \begin{array}{lllllll}1 & 2 & 0 & 2 & 1 & 1\end{array}$ practice strategies/techniques used in the PSEP?

7. Do you think you will $0 \quad 00 \begin{array}{llllll} & 0 & 0 & 1 & 2 & 4\end{array}$ be able to use PSEP strategies in other parts of your basketball playing or in life? 


\section{Appendix 0 \\ Control Post Questionnaire Results}

$\begin{array}{ccccccc}\text { not much } & \text { slightly } & & \text { somewhat } & \text { very } \\ 1 & 2 & 3 & 4 & 5 & 6 & 7\end{array}$

1. How effective were 0
$\begin{aligned} & \text { you in shooting free throws } \\ & \text { before training? }\end{aligned}$
$\begin{aligned} & \text { 2. How effective were o } \\ & \text { you in shooting free throws }\end{aligned}$
after training?

